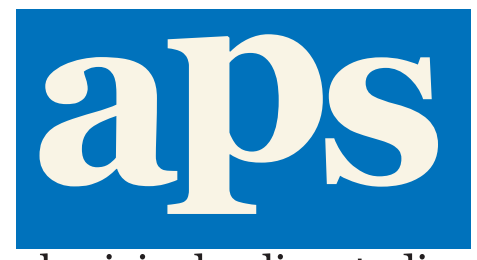

aboriginal policy studies

\title{
Article
}

\section{Urbanization and Migration Patterns of Aboriginal Populations in Canada: A Half Century in Review (1951 to 2006)}

\author{
Mary Jane Norris and Stewart Clatworthy
}

aboriginal policy studies, Vol. 1, no. 1, 2011, pp. 13-77

This article can be found at:

http://ejournals.library.ualberta.ca/index.php/aps/1/1/NorrisClatworthy.pdf

ISSN: 1923-3299

aboriginal policy studies is an online, peer-reviewed and multidisciplinary journal that publishes original, scholarly, and policy-relevant research on issues relevant to Métis, non-status Indians and urban Aboriginal people in Canada. For more information, please contact us at apsjournal@ualberta.ca or visit our website at

www.ualberta.ca/NATIVESTUDIES/aps/

or

http://ejournals.library.ualberta.ca/index.php/aps/ 


\title{
Urbanization and Migration Patterns of Aboriginal Populations in Canada: A Half Century in Review (1951 to 2006)
}

\author{
Mary Jane Norris, Consultant \\ and Stewart Clatworthy, Four Directions Consulting
}

\begin{abstract}
Within Canada, Aboriginal populations have historically experienced significantly different levels and patterns of urbanization and migration than mainstream populations have. This article uses data from selected Canadian censuses, along with earlier studies, to explore long long-term trends in Aboriginal urbanization and migration from 1951 to 2006. Migration between reserves and urban areas, and its role in the rapid growth of Aboriginal populations in urban areas, are considered from both historical and demographic perspectives, including a "components of growth" approach that assesses the contributions of migration, natural increase, and non-demographic factors (such as ethnic mobility and Aboriginal identity). The analysis of twelve major urban areas over the fifty-five-year period, including nine Urban Aboriginal Strategy (UAS) cities, suggests a preliminary typology of Aboriginal population growth in urban areas and implications for assessing the characteristics and needs of Aboriginal populations across different urban areas and the services provided for them.
\end{abstract}

\section{Introduction}

Aboriginal populations within Canada have, historically, experienced significantly different levels and patterns of urbanization and migration than mainstream populations. In this article, we use population and migration data from the census for twelve selected major urban areas to explore longterm trends in Aboriginal urbanization and migration between 1951 and $2006,{ }^{1,2}$ providing an overview of the urbanization and migration patterns

aboriginal policy studies, Vol. 1, no. 1, 2011

ISSN: 1923-3299

www.ualberta.ca/NATIVESTUDIES/aps/ 
of Aboriginal populations in Canada over the past half-century. Our study findings address three key areas:

- patterns and trends in Aboriginal population growth in urban areas;

- the role played by migration as a factor in the urbanization of Aboriginal populations; and,

- components of Aboriginal recent population growth in urban areas.

Based on the analytical results for selected urban areas, we propose a preliminary typology that distinguishes urban Aboriginal populations on the basis of population size, trends and components of growth, and period of urbanization. We conclude the article with some discussion of the differences between cities in terms of long-term patterns and components of Aboriginal population growth, as outlined in the preliminary typology, and consider their implications for the characteristics, needs, and services of Aboriginal populations living in a variety of urban areas.

\section{Urban Aboriginal Strategy (UAS) and UAS Cities}

By maintaining a focus on those major urban areas in Canada with significant Aboriginal populations, our study is relevant to the urban mandate of the Office of the Federal Interlocutor (OFI), including the Urban Aboriginal Strategy (UAS), given that many of the cities included in this study are "UAS cities." The UAS was first developed in 1997

to help respond to the needs facing Aboriginal people living in key urban centres ... The UAS operates in thirteen cities whose Aboriginal population represents more than 25 percent of Canada's total Aboriginal population. The thirteen designated cities include: Vancouver, Prince George, Lethbridge, Calgary, Edmonton, Prince Albert, Regina, Saskatoon, Winnipeg, Thompson, Toronto, Thunder Bay and Ottawa (see http://www.ainc-inac.gc.ca/ai/ofi/ uas/bkg-eng.asp).

Our own analysis of urbanization and migration of Aboriginal populations conducted for this study focuses on twelve cities, including Winnipeg, 
Edmonton and Vancouver, Calgary, Toronto, Saskatoon, Ottawa/Gatineau, Montreal, Regina, Thunder Bay, Sudbury, and Hamilton. The findings and implications of this study will have direct relevance for nine of the thirteen UAS cities, excepting Prince George, Prince Albert, Lethbridge, and Thompson.

\section{Background: History of Urbanization of Aboriginal Populations in Canada}

Observers of Aboriginal urbanization suggest that the beginnings of Aboriginal population growth in "urban" areas within the context of Canadian geography ${ }^{3}$ were starting to appear after the first half of the twentieth century. According to the 1951 Census, few Aboriginal people resided in urban areas, numbering only in the hundreds in most cities. Between the censuses taken in 1951 and 1961, urban Aboriginal populations (based on mainly "Indian" populations as referred to in these censuses) started showing signs of growth, with some urban areas experiencing increases of over 50 percent in their Aboriginal population. As Mark Nagler observed in his study "Indians in the City," "Census figures reveal that growth in the Indian urban population is substantial ... Indians are entering urban areas at an unprecedented rate" $(1973,7)$.

By the time of the 1971 Census, the numbers of Aboriginal people living in urban areas had increased significantly, as highlighted in the 1974 Statistics Canada report "Perspective Canada." To quote W. T. Stanbury, "The 1971 Census indicated that there were 1,000 or more Indians in twelve urban centres in Canada. In seven of these cities there were more than 2,000 Indian residents" (1975, xxiii ).

Field literature documents the rapid rise in the numbers of urban Aboriginal peoples over the decades following the initial period of urbanization in the 1960s (Clatworthy 1981; Peters 2000). A number of recent demographic studies have documented the especially pronounced growth of the urban Aboriginal population during the twenty-year period from 1981 to 2001 (Guimond, 2003a; Siggner and Costa, 2005).

While the migration by Aboriginal people to cities may have fuelled the urbanization of Aboriginal populations at the outset of the study period, various demographic analyses have consistently revealed, particularly over the more recent past twenty-five years of this fifty-five year period, that many other factors have since come into play. Not the least of these was 
"Aboriginal Identity" (Guimond 1999; 2003a; 2003b; Guimond, Robitaille, and Senecal 2009; Norris and Clatworthy 2003a; 2003b; Siggner and Costa 2005).

\section{Objectives of a Census-Based Analysis}

The research for this article uses population and migration data from Canadian censuses for twelve selected major urban areas, including nine of the UAS cities where data permit, to explore long-term trends in Aboriginal urbanization and migration, starting in 1951 and ending in 2006. Among the four different Aboriginal populations - First Nations, Registered and NonStatus Indians, Métis, and Inuit-Registered Indians are the only Aboriginal group for whom reasonably consistent census data exists back to the 1960 s.

In this article, we present data on long-term trends in urbanization for the overall Aboriginal population and, where available, for the four different Aboriginal populations. Distinguishing a population on the basis of Indian registration status is important to any analysis of Aboriginal mobility or migration. Unlike other Aboriginal groups, individuals registered under the Indian Act have certain rights and benefits, especially if they live on reserve, such as access to funding for housing and post-secondary education, as well as land and treaty rights. These factors can be important to understanding differences in the migration patterns of the four Aboriginal subgroups. Although data and analyses for the early portion of the study period are based primarily on the Registered Indian population, we recognize that levels and patterns of urbanization and migration do vary across different Aboriginal populations (Clatworthy and Norris 2007; unpublished paper; Norris et al. 2003; Norris and Clatworthy 2003b).

This census-based analysis is designed to address several related research objectives. The first is to identify historical and long-term patterns in the urbanization of Aboriginal populations in Canada, for urban areas overall, and-for selected cities-between 1951 and 2006. The second examines migration as a factor in the urbanization of Aboriginal populations from both historical and demographic perspectives, including its contribution to the more recent and rapid increase of Aboriginal population in large urban areas. We use a "components of growth" approach to assess the contribution of migration and other factors, including ethnic mobility and natural increase, to recent growth of urban Aboriginal populations. As such, this approach clarifies some of the misinterpretations surrounding 
migration, such as the impression that the recent demographic explosion of urban populations is largely the result of an exodus from reserves.

Another major objective is to assess regional patterns, trends, and variations in Aboriginal migration and population growth for specific, selected urban areas across Canada. The analysis for these various urban areas provides an estimate of the impact of different components of Aboriginal population growth, such as natural increase, and the identification of the different types of long-term patterns and components of Aboriginal population growth across major urban areas.

Finally, we use the results of this census-based analysis for select urban areas to construct a preliminary typology of urban Aboriginal populations based on growth patterns, population size, and components of population growth. We conclude the article with some initial thoughts on the relevance and implications of the typology in relation to the characteristics, needs, and service demands of Aboriginal populations living in different urban areas.

\section{Census Data on Aboriginal Urbanization and Migration 1951 to 2006: Concepts, Definitions, Limitations, and Coverage}

Censuses conducted between 1951 and 2006 have been subject to significant changes in conceptualization, definitions, geography, and coverage. These changes have affected data on the population in general, and Aboriginal populations especially, to such an extent that data on Aboriginal urbanization and migration are not fully comparable across censuses.

\section{Aboriginal Population Definitions and Concepts}

Details about Aboriginal population data and their limitations as found over the course of the censuses taken between 1951 and 2006 are presented in two sections: "Aboriginal Populations 1951 to 2006: Census Concepts and Definitions used in This Study" and "Comparability and Limitations of Aboriginal Population Data across Censuses." These two sections can be summarized in three key points:

1. The "Aboriginal population" as a whole varies in definition and composition over the fifty-five-year period of analysis. Between 1951 and 1986, the Census defined Aboriginal populations on the basis of 
"ethnic origins" (ancestry). Before 1981, ancestry was traced only on the father's side, and restricted to single origins. Also, the total Aboriginal population comprised just Indian and Inuit; after, in 1981, the Census incorporated the category of Métis, and made distinctions between Non-Status and Registered Indians. The analysis in this article uses data on Aboriginal populations, as defined on the basis of “Aboriginal Identity," from 1996 on, when they first became available.

2. Most aspects of the long-term trends from 1951 to 2006 refer to the Aboriginal population as a whole rather than making distinctions between the different Aboriginal groups. Due to data availability and comparability, as well as approach, some dimensions, address longterm patterns only for some specific Aboriginal populations, such as migration, starting in the 1961 for the Registered Indian population only; or similarly, only certain time periods, such as the urban populations for all four different Aboriginal groups, available only from 1981 on.

3. Limitations in the comparability of Aboriginal populations across censuses also affect the measurement of intercensal changes in Aboriginal population size. Estimates of average annual growth can be under- or over- estimated for various periods. For example, growth estimates over 1961 to 1971 could be understated due to exclusion of Inuit populations from published 1971 counts; while growth between1981 ancestry-based and 1996 identity-based populations could be underestimated given the switch from origin to identity numbers, since the latter tend to be lower.

\section{Aboriginal Populations 1951 to 2006: Census Concepts and Definitions Used in This Study}

The following discussion addresses current concepts and definitions, and highlights changes made to them since 1951 that affect comparability of populations across censuses.

Current Censuses: 1996, 2001, and 2006

The three most recent censuses $(1996,2001$, and 2006) allow the Aboriginal population to be defined according to a number of different concepts and criteria, including ethnic origin (ancestry); Aboriginal identity (self-reported affiliation with Aboriginal group), Registered Indian (legal status), and First Nation Affiliation or band membership. 
Analyses in this paper for the 1996-2006 period are based on the population that reported an Aboriginal identity (North American Indian, Métis, or Inuit), and/or reported registration under the Indian Act, and/or reported membership in an Indian band or First Nation. According to the 2006 Census, this population numbered about 1,172,790 individuals, including 698,025 North American Indians (59.5 percent), 389,780 Métis (33.2 percent), 50,480 Inuit (4.3 percent) and 26,760 others who gave either multiple Aboriginal responses or did not report identity but did report Indian registration or band membership. The population reporting Indian registration numbered 623,780 , representing 53.2 percent of the total population reporting Aboriginal identity.

For the purposes of this study, Aboriginal populations from 1996 to 2006 have been configured into four groups: 623,780 Registered Indians (regardless of Aboriginal identity); non-registered 133,160 Indians; 355,500 Métis (non-registered); and 49,110 Inuit (non-registered) (see Clatworthy and Norris, 2007; forthcoming).

\section{Censuses Prior to 1996}

Since the 1871 Census, the Aboriginal population in Canada has been traced through the question asked about ethnic origin/ancestry/race (i.e., ethnic affiliation of respondent's ancestors). However, over time, censuses have seen changes in the measurement of ethnic origin or ancestry. Prior to 1981, only single origins traced on the father's side were permitted. The 1981 Census saw the introduction of "multiple responses," which "allowed" maternal, as well as paternal, origins. However, the impact of multiples on the size of the Aboriginal origin population was not felt until 1986, when respondents were instructed to report as many groups as applicable; consequently “ . . 1981 and 1986 census data on ethnic origins are not directly comparable because of differences concerning multiple responses" (Norris 1996, 183). Hence, 1981 counts of single and multiple Aboriginal origins are mostly single-based, and in effect closer to Identity-based measures.

Censuses counts of Aboriginal populations for the 1951, 1961, 1971, 1981, 1986, and 1991 censuses were based on "ethnic origin." Censuses prior to 1981 employed the terms "Indian" and "Inuit." 1981 saw the introduction of the "Registered Indian" category in lieu of the term "Band Indian" and, for the first time since 1941, the return of "Métis" as an ethnic origin option. The 1986 Census first introduced the new concept of Aboriginal population based on ethnic identity-self-identification (i.e., North American Indian, Métis, Inuit) (Norris, 1996). The concept of Aboriginal identity was also used in the 1991 Aboriginal Peoples Survey (APS); however, it was not until the 1996 Census that the question on Aboriginal identity was reintroduced and data were released. ${ }^{1}$

1 While the concept of Aboriginal identity was first introduced in the 1986 Census, data on identity were never officially released owing to reporting errors detected within the population reporting no Aboriginal origin. However, data on identity with Aboriginal origin are reliable (Guimond 2003a). 


\section{Comparability and Limitations of Aboriginal Population Data across Censuses: Factors Affecting Estimates of Intercensal Population Growth Intercensal variations in coverage and incomplete/partial enumeration: ${ }^{1}$}

With the exception of Montreal, census data have not been adjusted for intercensal variations in undercoverage and incomplete/partial enumeration of reserves/settlements. In the case of Montreal, Siggner and Costa have excluded the Kahnawake reserve from the 1981 count for comparability with later censuses, as the reserve has been incompletely enumerated since 1981 (Siggner and Costa, 2005).

Composition of Aboriginal population: Estimates of intercensal Aboriginal population growth in urban areas can be affected to some extent by changes in the composition of the Aboriginal population. Published estimates from the 1951 and 1961 censuses include both Indian and Inuit, whereas published estimates for 1971 reflect Indian counts only. To some extent these changes may affect growth estimates, underestimating 1961-1971 growth, though this is less likely an issue in urban areas. Estimates of growth for the 1971-1981 period may be overstated as a consequence of the inclusion of both multiple responses (to ethnic origin) and the Métis category as an ethnic origin response.

Switch from Ancestry counts in 1981 to Identity counts in 1996: Although the 1981 Ancestry and 1996 Identity counts of Aboriginal populations are not directly comparable, they have been used in trend analyses (Siggner and Costa 2005). However, the conceptual comparability of 1981 Ancestry and 1996 Identity counts is not as limited as might be first expected. Ancestry numbers, as seen from 1996 on (when Identity counts became available), which reflect single and multiple origins, are significantly higher than Identity numbers (e.g., 1.1 million vs. 799,000 in 1996). Yet, 1981 Ancestry counts of single and multiple origins are largely single-based, at 491,500, especially when compared to 1986 Ancestry counts of $711,725$ (with single origins numbering 373,260$)$ and multiple origins $(338,460)$ (Norris 2000 , 192, 196). 1986 Identity estimates are at 464,455 (Guimond 2003b, 93), and the 1981 Ancestry counts of largely single-based origins, compared to 1986, are significantly lower in number than those from the Ancestry-based single and multiple origins, but closer to the Identity counts. To some extent, single-only based origins of 1981 Ancestry are conceptually more likely to reflect Identity-based than Ancestry-based populations. Thus, although the growth between 1981 Ancestry-based and 1996 Identity-based populations would be underestimated, to some degree, our analysis nevertheless suggests the 1981 Ancestry count appears to be more compatible with the 1996 Identity, rather than Ancestry, counts.

1 The term "incompletely enumerated" refers to those Indian reserves and Indian settlements in the census where "... enumeration was not permitted or was interrupted before it could be completed. Moreover, for some Indian reserves and Indian settlements, the quality of the enumeration was considered inadequate." (http://www12.statcan.ca/census-recensement/2006/ref/notes/aboriginal-autochtones-eng.cfm) 
Exclusion of 1981-1986, 1986-1991, 1991-1996 intercensal periods: Between the 1981 Ancestry and 1996 Identity populations, total Aboriginal counts for the intervening censuses of 1986 and 1991 are based on single and multiple Aboriginal origins, which are not compatible with a time series based largely on single Aboriginal origins or Identity. Consequently, the 1986 and 1991 censuses, as well as the 1976 Census (for which long-form data was not collected) are not included in our time series. As such, we advise caution in the interpretation of longterm trends in population growth for broader intervals, such as the fifteen-year period between 1981 and1996, where average annual growth rates mask the intercensal changes of the three five-year periods of 1981-1986, 1986-1991, and 1991-1996.

One observation to note in relation to this analysis of intercensal growth of Aboriginal populations is the transition in time series in 1996 from Ancestry- to Identity- based population data. The rationale for this transition will be explained later in this article, in the section "Comparability and Limitations of Aboriginal Population Data across Censuses." It is the case that the growth between 1981 Ancestry-based and 1996 Identitybased populations could be underestimated to some degree, since Identity numbers tend to be lower in general than origin or Ancestry numbers. However, because the 1981 Ancestry count of single and multiple origins is largely composed of single origins, it appears to be more compatible with the Identity than the Ancestry counts of the total Aboriginal population in 1996. Consequently, the time series of Aboriginal population can be best described as a series of single-origin Ancestry (1951 to 1981) and Identity (1996 to 2006) data.

\section{Geographic Definitions of Urban Areas and Cities}

Three different sets of geography concerning urban areas are used in this analysis, two at the national level and the third at the level of individual cities. Details on the definitions and concepts are found in the subsection "Geography of Urban Areas / Cities: Census Concepts and Definitions Used in Study." 
Urban, Rural, and Reserve Geographies at the National Level

We used different configurations of urban geography in this study. We examine long-term trends in Aboriginal populations in urban areas in terms of total urban areas overall, and for the major large urban centres known as census metropolitan areas (CMAs).

1. For analysis of residential distributions and migration patterns of Aboriginal populations at the Canada level, we employed customized census geographies, including those based on CMAs and CAs (Census Agglomerations), that were adjusted to exclude reserves and rural fringes and to yield four mutually exclusive and exhaustive geographic areas;

2. large urban areas-Urban CMAs (excluding reserves and rural fringes);

3. smaller urban areas-Urban non-CMAs(all other urban areas, including urban CAs and smaller urban areas);

rural areas; and,

4. Indian reserves and settlements.

Geography of Twelve Individual Urban Areas / “Cities” from 1951 to 2006

This study referenced data, at the level of individual urban areas, on Aboriginal populations that were available for twelve cities from selected censuses spanning the period 1951-2006. These cities include: Winnipeg, Edmonton and Vancouver, Calgary, Toronto, Saskatoon, Ottawa/Gatineau, Montreal, Regina, Thunder Bay, Sudbury, and Hamilton. The geography that was available for the twelve "cities" or urban areas with Aboriginal populations varied from 1951 to 2006. For the period 1951 to 1981, data are provided for the urban area at the Census Subdivision level (CSD) with the CSD Type of "City"; from 1971 to 2006, cities are based on the Census Metropolitan Area (CMA) level corresponding to the particular urban area. In order to accommodate differences in geographic units between the 1971 and 1981 Censuses, two sets of city-level counts are provided for the two different levels of geography-CSD and CMA. 
In the case of individual cities, it was not possible with the available historical data to exclude reserves consistently from cities. Thus, unlike urban areas overall at the national level, reserves are generally not excluded from the CMA/CA of individual cities, with the exception of Montreal in 1981. The 1981 Census data on Aboriginal population in Montreal were adjusted to exclude Kahnawake (from Siggner and Costa 2005) for comparability with later censuses, since after 1981 this reserve has been incompletely enumerated over each subsequent census. Thus, data on Aboriginal populations for Montreal 1981 are shown twice: first, including Kahnawake, for comparability with the previous 1971 Census counts; and, second, for excluding Kahnawake for comparability with population data for censuses in the series from 1996 on.

\section{Comparability of Geography across Censuses}

Geographic classifications and boundaries for reserves, cities, and CMAs can change, as can their rural/urban classifications, from one census to the next. In this study, census data have not been adjusted for these intercensal changes. However, to some degree, intercensal changes in urban boundaries associated with the reclassification of formerly rural areas to urban can contribute to the urbanization of Aboriginal people. An early example of this process of urbanization is reflected in the observation that, in the case of Métis, prairie cities grew up around Aboriginal people, rather than Aboriginal people urbanizing (Newhouse and Peters 2003).

\section{Census Migration Data and Definitions}

The Census of Canada collects mobility and migration data using two questions:

- Where did you live five years ago?

- Where did you live one year ago?

Data from either question can be configured to distinguish among three subgroups:

- Non-movers, who lived at the same residence at the outset of the reference period (i.e., either five years ago or one year ago); 


\section{Geography of Urban Areas / Cities: Census Concepts and Definitions Used in this Study at the National and City Levels}

\section{Urban, Rural, and Reserve Geographies at the National Level}

Different types of urban areas comprise census geography. The census defines an urban area as having

a population of at least 1,000 and no fewer than 400 persons per square kilometre . . All territory outside urban areas is classified as rural. Taken together, urban and rural areas cover all of Canada. Urban population includes all population living in the urban cores, secondary urban cores and urban fringes of census metropolitan areas (CMAs) and census agglomerations (CAs), as well as the population living in urban areas outside CMAs and CAs" (Statistics Canada 2010, 231).

A CMA is defined on the basis of urban areas with a minimum core population of 100,000 ; similarly, a minimum of 10,000 is required for a CA. Reserves, as well as rural fringes, can lie within both CMAs and CAs.

Different configurations of urban geography were used in this study, including "Total Urban Areas," CMAs (including both urban areas and rural fringes), urban CMAs (excluding reserves and rural fringes), and urban non-CMAs; that is, all other urban areas (including urban areas of CAs and smaller urban areas). We examine trends in Aboriginal populations in urban areas in terms of total urban areas and CMAs, and examine residential distributions and migration patterns of Aboriginal populations within the context of four mutually exclusive and exhaustive geographic areas: urban CMAs, urban non-CMAs, rural areas, and, Indian reserves/ settlements.

Unlike individual cities (with the exception of Montreal in 1981), for urban geographies at the Canada level, as noted earlier, we employed customized CMA and CA geographies to yield the four mutually exclusive geographic areas to enable our analysis of residential distributions and migration flows. Indian reserves, as well as rural fringe areas located within CMA or CA boundaries, are excluded. Similarly, rural areas comprising all remaining areas include the rural fringes of urban areas, but exclude Indian reserves and settlements. Apart from reserves, other Aboriginal communities (e.g., Inuit, Métis) lie within rural and urban non-CMA areas. 


\section{Geography of Twelve Individual “Cities” From 1951 to 2006}

Reserves are located within the boundaries of some of the individual cities in this study, such as Montreal and Vancouver. The published census data available on Aboriginal populations in individual cities (especially from earlier censuses) include reserves located within city boundaries, and city-level data adjusted to exclude reserves are not easily available. The only exception to this is 1981 data for Montreal, where the reserve of Kahnawake is located. Siggner and Costa have adjusted the 1981 data on Montreal to exclude Kahnawake, for comparability with later censuses, since this reserve has been incompletely enumerated since 1981 .

CSD and CMA geography for the twelve "cities" varies from 1951 to 2006. For the 1951 to 1981 period, available data are provided for the urban area at the Census Subdivision level (CSD) with the CSD Type of "City." "Census Subdivision" is the general term for a municipality or an area deemed to be equivalent to a municipality for statistical reporting purposes. There are fifty-five different CSD types, such as city, Indian reserve, and unorganized territory (Statistics Canada 2010,211-12). Population counts of cities are provided for both CSD and CMA for 1971 and 1981, and CMA only from 1996 on.

- Migrants, who lived in a different community/census subdivision (e.g., municipality, town, village, reserve) at the outset of the reference period;

- Residential or non-migrant movers, who lived at a different residence in the same community at the outset of the reference period.

Thus, a "migrant" is a mover who changed communities, whereas a "residential" or "non-migrant" mover is a mover who changed residences within the same community. Combined, the latter two groups comprise the total population of movers during the reference period. The migration components of the analyses presented in this paper use data from the fiveyear mobility question. Migration rates are presented both as five-year and average annual rates computed for the five-year period.

Census migration and mobility data present some conceptual limitations, some of which tend to be more pronounced for the five-year than the one-year question, given the longer time period. For example, many characteristics of migrants, such as age, education, marital and family status, and socio-economic attributes, are known only at the end of migration reference period (i.e., at the time of the census), and may differ 
at the time of migration. The census also does not capture multiple moves, migrants who leave and return to the same location, or those who die during the time interval. Because of its shorter one-year interval period, the oneyear data can provide a more accurate picture for a given year of migration patterns, volumes, and characteristics, as compared to the five-year question. However, the limitation is that the year in questioncould be an unusual or volatile time period and so may not be typical of longer trends. In this sense, the five-year question provides a more reliable portrayal of mobility patterns and trends, and one even more so for migration (Norris and Clatworthy 2003).

\section{Coverage Issues}

While the census provides the most complete and consistent set of data concerning the urbanization and migration patterns of Aboriginal peoples, the data are limited in a number of respects. Census questions on ethnicity, identity, and mobility are only administered to a sample of the total census population, which excludes individuals living in various institutions, including prisons and chronic care facilities, along with those who are living in rooming houses. The fact that these persons are "missed" is a relevant consideration, given that Aboriginal people constitute a disproportionately high share of the population living in these situations, particularly in urban areas, where persons who are homeless or in rooming houses tend to be located.

Aboriginal population data from the census are also affected by incomplete enumeration of Indian reserves, as well as survey undercoverage both on and off-reserve. Incomplete enumeration and undercoverage can affect population counts and geographic distributions of all Aboriginal populations. Population counts of Registered Indians on reserves are underestimated, due both to incomplete enumeration of various reserves and undercoverage in general. Off-reserve counts of other Aboriginal populations, as well as those of Registered Indians, are also affected by undercoverage in urban and rural areas. As a consequence, the geographicresidential distributions of Aboriginal populations enumerated in the census can be biased with respect to proportions residing on or off-reserve, or in urban or rural areas. In addition, the extent of incomplete enumeration and survey undercoverage varies from one census to another, and as a consequence can impact on estimates of intercensal population growth. 
The impact of undercoverage of Aboriginal populations in urban areas on census population counts is not new. In fact, under-enumeration of Aboriginal people in urban areas was recognized as early as the 1970s, as Nagler observed in his paper "Indians in the City":

Anyone spending time in one of these (urban) centres would soon realize that Indians living in the city are grossly under-enumerated by the census. The under-enumeration occurs because many urban Indians reside with friends or in rented rooms . . . hotels, and other transient dorms which seldom if ever fall under the scrutiny of the census taker $(1973,7)$.

The potential for underestimation of Aboriginal populations in urban areas that Nagler stressed back in the early 1970s continues to remain an issue, especially in light of the high mobility of Aboriginal populations and the fact that census-based Aboriginal population counts do not include people in institutions, rooming homes, or other forms of collective dwellings.

\section{External Limits to Comparability across Censuses}

While it is important to consider the limitations of data comparability in assessing long-term census-based trends in Aboriginal urbanization

and migration, it should nevertheless be stressed that it is difficult, if not impossible, to isolate and unravel all the impacts on census comparability. External changes, such as those associated with the effects of transportation and accessibility on location, residence, and migration, as well as changing Aboriginal population composition and concepts (i.e., ancestry and identity) and geographic boundaries and rural/urban classifications can all contribute to limitations of comparability over time.

\section{Approach, Methodology, Limitations, and Considerations}

In this study of Aboriginal urbanization and migration, we employ both demographic and historical approaches in analysing patterns and trends over the past fifty years. It should be noted that, as with any study, there are limitations, and one aspect of urbanization in particular that this study recognizes but does not assess here is the "urbanization" of areas with existing Aboriginal populations. 


\section{Approach and Methodology}

With respect to the long-term analysis of urbanization, our analyses are based on available published census data on Aboriginal populations in urban areas. Owing to constraints of time, data availability, and comparability, not all census years, such as 1986 and 1991, are included in the trend analysis. The study also highlights longer-term population trends and patterns in urbanization for twelve selected major urban areas with large Aboriginal populations, using data for selected censuses spanning the time period from 1951 to 2006. Though limited with respect to data comparability over time, the approach and methodology provide a general idea of the trends and patterns in Aboriginal urbanization over the period studied.

We complement trends in urbanization identified using census data with historical perspectives of urbanization and migration from the literature that reflect observations of migration and urbanization from various points in time over the study period.

We employ a "components of growth" approach to assess the contribution of migration and other factors to recent (1996-2001) urban growth. The approach separates population changes observed for the time period into four main components: natural increase (i.e., the excess of births over deaths); net migration (i.e., in-migrants minus out-migrants); changes in survey coverage; and ethnic mobility. Ethnic mobility, or ethnic drift, is defined as changes in self-reporting of ethnicity and, specifically in this study, refers to changes in individual self-reporting of Aboriginal identity from one census to another. Demographic research has demonstrated that this phenomenon has been a significant factor in the more recent growth of Aboriginal populations in Canada, especially in urban areas (Guimond 1999; 2003a; 2003b; Guimond, Robitaille, and Senecal 2009).

Other aspects of the methodology include various migration measures, such as in, out, and net migration rates in relation to the impact of migration on urban population change, and gross migration rates (i.e., in rates plus out rates) as indicators of urban population turnover.

\section{Limitations and Considerations}

As discussed in the section "Geography of Urban Areas / Cities: Census Concepts and Definitions Used in Study," census data used in this long-term 
approach have not been adjusted for intercensal variations in undercoverage and incomplete/partial enumeration, or for changes in geographic boundaries over censuses. As well, with the exception of Kahnawake in 1981, reserves located within individual CMAs are not excluded.

\section{Considerations Re "Urbanization" of Areas with Existing Aboriginal Populations}

With respect to assessing long-terms trends in urbanization, this paper utilizes mainly a demographic component approach in assessing the contribution of different factors, including natural increase, migration, and, for more recent periods, ethnic mobility, to the growth of the Aboriginal populations in urban areas. However, as indicated earlier, another facet of Aboriginal urbanization, and one not directly addressed here, involves the geographic aspect of the "urbanization" of an area or "territory" with significant existing Aboriginal populations (as in the case of Métis in prairie cities), where cities grow up around Aboriginal people rather than Aboriginal people "urbanizing."

Preliminary results from census-based research over the most recent ten-year period between the 1996 and 2006 Censuses (Jette and Snider 2009) appear to provide some evidence and measure of the geographic component of "urbanization of areas with existing Aboriginal population" as a contributing factor in the trends of Aboriginal urbanization. Findings, controlling for intercensal changes in incomplete enumeration of communities, show an increase of 11.4 percent (from 176 to 196) in the number of North American Indian or First Nation (FN) CSDs that are "affiliated" or located within CA/CMA areas. Corresponding to this growth in the number of First Nation CSDs, the proportion of FN CSDs with a CA/ CMA affiliation increased by 11.6 percent from a total percentage of 16.4 in 1996 to 18.3 in 2006 (Jette and Snider, Table 3).

As well, the population associated with the rising number of individual FN CSDs located within cities saw a 34.5 percent increase over the ten-year period, from 49,600 in 1996 to 66,700 in 2006, and a corresponding 9.3 percent increase in the proportion of $\mathrm{FN}$ residents living within $\mathrm{CA} / \mathrm{CMA}$ areas (from $18.2 \%$ to $19.9 \%$ ) (Jette and Snider, Table 5).

Assessment of the contributors to this growth include the factors and rules associated with the delineation of CA and CMA boundaries over time, such as commuting patterns, spatial contiguity, and historical comparability. 
The authors found that:

most changes in the CA/CMA affiliation of First Nation communities are not attributable to changes in commuting patterns over intercensal periods, and conclude in their findings that ". . . based on available data, in most cases inclusion of First Nations in a CA/CMA cannot be attributed to factors occurring within the First Nation communities themselves; however in these cases their inclusion is nevertheless justified by external factors, i.e. urban growth/sprawl" (Jette and Snider). . .These preliminary findings would suggest that the geographic affiliation of First Nation CSD communities with urban zones based on CA/CMA geography reflects the presence of phenomena-distinct from mobility trends or natural urban Aboriginal population growththat are contributing to urbanization of the Aboriginal population in Canada (Personal communication, D. Jette, 7 May 2010).

Thus, in this demographic analysis of long-term trends in Aboriginal urbanization, it is recognized that the geographic "urbanization of Aboriginal territory" also underlies some of the observed change over censuses in the Aboriginal population residing in urban areas. However, it should be emphasized that, with respect to the demographic component approach, assessment of both population growth and the components of that growth (e.g., natural increase, migration, and ethnic mobility) does control for intercensal changes in CA/CMA boundaries according to the most recent census (e.g., 2006 boundaries are used in the case of boundary changes between 2001 and 2006).

\section{Historical (1951 to 1981) Patterns and Trends of Aboriginal Urbanization in the Literature}

\section{A Half Century of Trends-Significant Growth after 1951}

In the thirty years between 1951 and 1981, Aboriginal populations residing in Canada's urban areas experienced considerable growth. In 1951, the Aboriginal populations of most urban areas numbered only in the hundreds. As noted by Nagler (1973), however, the populations of several urban areas posted increases of over 50 percent during the decade between 1951 and 1961. By 1971, seven urban areas had more than two thousand Aboriginal 
residents, including Winnipeg (4940); Edmonton (4260); Montreal (3215); Vancouver (3000); Toronto (2990); Regina (2860); and Calgary (2265) (Stanbury 1974; Statistics Canada Perspectives 1974).

Another separate indicator from the Indian Register of Indian and Northern Affairs on the proportion of Registered Indians living off-reserve also reflected population growth outside reserves over roughly the same time period. Over the 1960s, the share residing off-reserve increased significantly, from 17 percent in 1959 to 28 percent by 1972 (Stanbury 1974).

Rapid growth of Aboriginal populations in urban areas appeared to be especially common in western Canada during this early period of urbanization. As Stewart Clatworthy observed in 1981, in reference to the twenty-year period of growth up to 1981 ,

The past two decades have witnessed the movement of increasing numbers of native persons from rural areas and reservations to urban centres. Although this phenomenon has occurred in all regions of Canada, it has been especially pronounced in Canada's western provinces and has led to the very rapid growth of native populations in major prairie cities. . ." (Clatworthy 1981, from Sharzer 1985, 556).

\section{More Recent (1981 to 2006) Patterns and Trends of Aboriginal Urbanization in the Literature}

Following the initial period of urbanization observed during the 1960s, the 1970s and 1980s saw the continuation of substantial levels of growth in Aboriginal populations in urban areas, especially for some prairie cities. As Evelyn Peters observed,

By 1991, several prairie cities had very substantial populations of Aboriginal people, and it is likely that for many cities, the absolute increase between 1981 and 1991 was greater than the increase between 1971 and $1981(2000,247)$.

In their study "Aboriginal Conditions in Census Metropolitan Areas, 1981 to 2001," Siggner and Costa highlighted the phenomenal growth experienced in cities with large Aboriginal populations: 
The Aboriginal population in these cites has grown dramatically over the 20-year period. . . . The Aboriginal population in the selected CMAs more than doubled in 20 years and in some cities quadrupled, such as in Saskatoon $(2005,5)$.

In his study of Aboriginal population growth, Eric Guimond observed that the Aboriginal identity population experienced exceptional growth between 1986 and 1991, most notably in urban areas:

The overall exceptional growth of Aboriginal identity populations during the period 1986-91 occurred off Indian reserves, especially in urban areas: 6.6 and 9.4 percent per year respectively in rural and urban areas (Guimond 2003a, 40).

\section{Selected Urban Areas: Patterns and Trends in Aboriginal Urbanization, 1951 to 2006}

\section{All Urban Areas and CMAs}

Turning now to the data, we begin with a look at long-term trends in the percentage of the total Aboriginal population residing in all urban areas (large and small combined) and large census metropolitan areas (CMAs) from 1961 to 2006. Figure 1 shows that the proportion residing in urban areas has increased steadily, from just 13 percent in 1961 to 53 percent by 2006, while the proportion residing in CMAs rose from 7 percent to 31 percent. Similar to Figure 1, but instead for the different Aboriginal and nonAboriginal populations starting in 1981, Figure 2 provides the percentage of the Aboriginal Population residing in all urban areas, while Figure 3 shows the corresponding percentage in CMAs. First, to situate the comparison, trends between 1961 and 2006 show the steady increases in the percentages of the Aboriginal population overall in urban areas (Figure 2) and CMAs (Figure 3), rising to 53 percent and 31 percent respectively by 2006 . However, the overall Aboriginal population, in spite of increasing trends in urbanization, remains less urbanized than the non-Aboriginal population, with 81 percent and 65 percent in urban areas and CMAs respectively. 
From 1961 to 2006, the proportion of the Aboriginal population residing in urban areas has increased steadily from just $13 \%$ to $53 \%$.

60 The proportion residing in large metropolitan areas (CMAs) has also increased from $7 \%$ to $31 \%$.

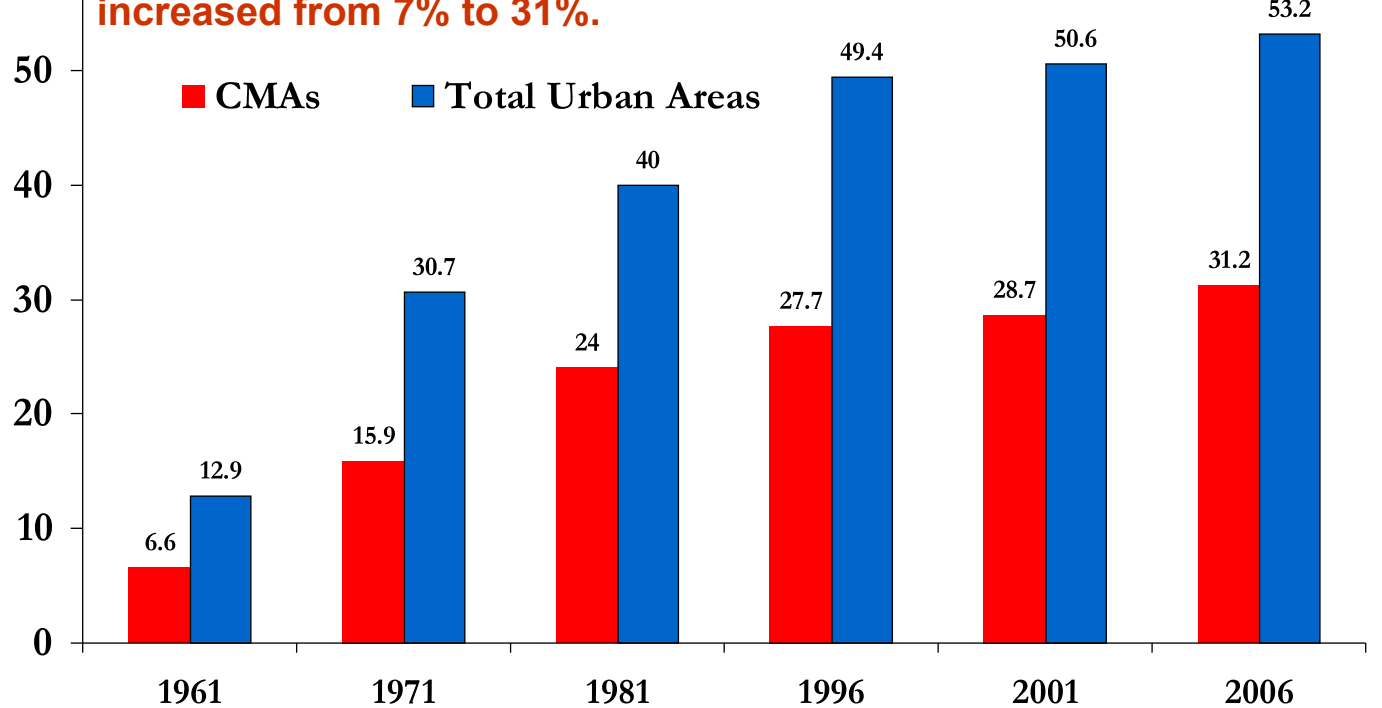

Sources: Authors' calculations based on Statistics Canada publications on Census of Canada data: 1961, 1971 City-level (including 1951) from Perspective Canada 1974, Cat. No. 11-507 E, Table 12-9, page 244; 1971 City and CMA Ethnic Groups; 1981 City and CMA (Ethnic Origin); 1981, 1996, and 2001 CMA, Siggner and Costa 2005; 2006 Census of Canada (see Section 6.1 for details).

Figure 1: Percentage of Total Aboriginal Population Residing in All Urban Areas, 1961 to 2006.

Aboriginal groups differ in their trends and degrees of urbanization, although all have experienced increased urbanization.

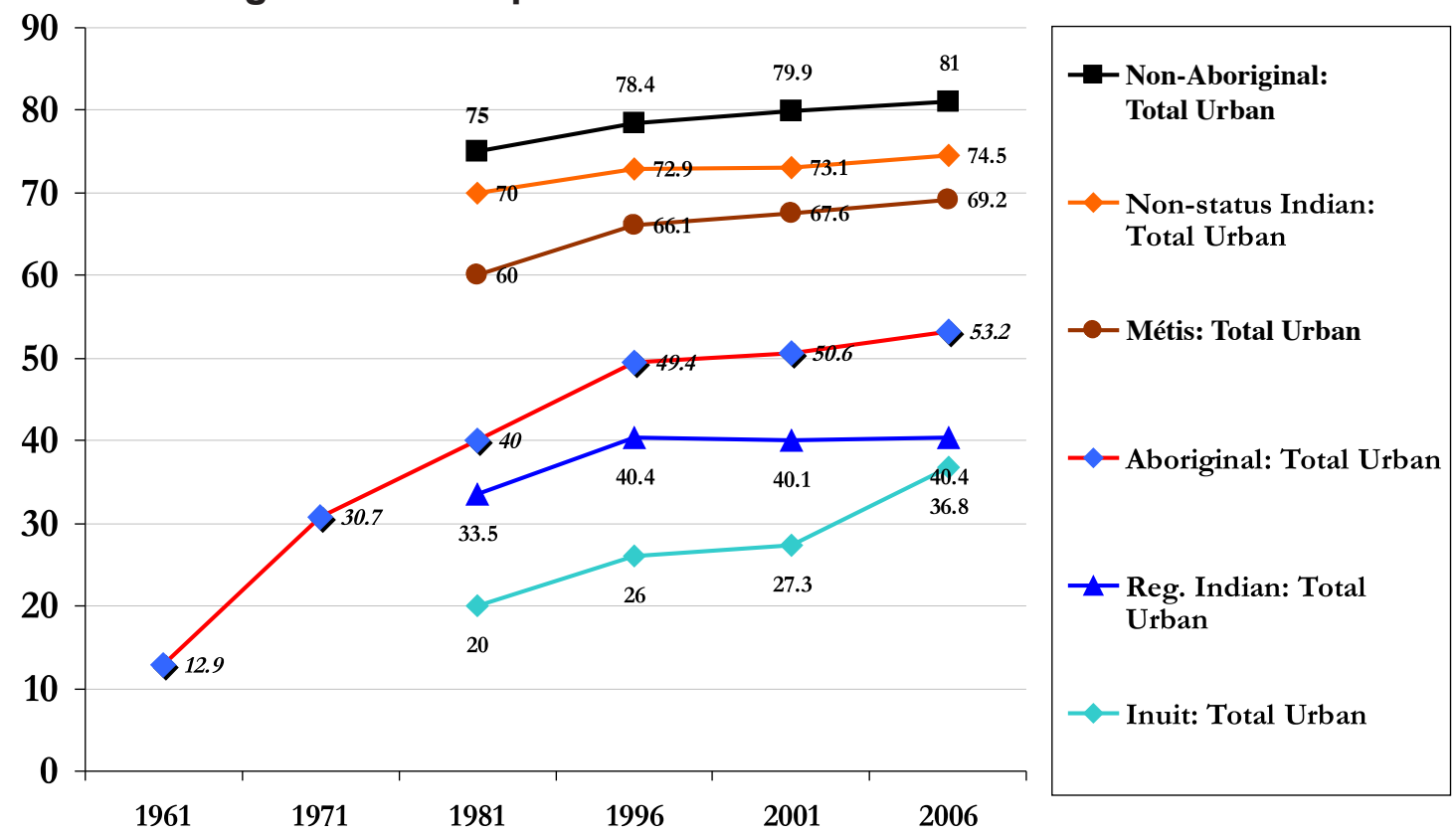

Sources: See Figure 1. Aboriginal groups 1971 to 2006 from Clatworthy and Norris 2007; unpublished paper; Norris, Cooke, and Clatworthy 2003; Norris 2000; 1996.

Figure 2: Percentage of Aboriginal Populations in Total Urban Areas, for Selected Census Years, 1961 to 2006. 


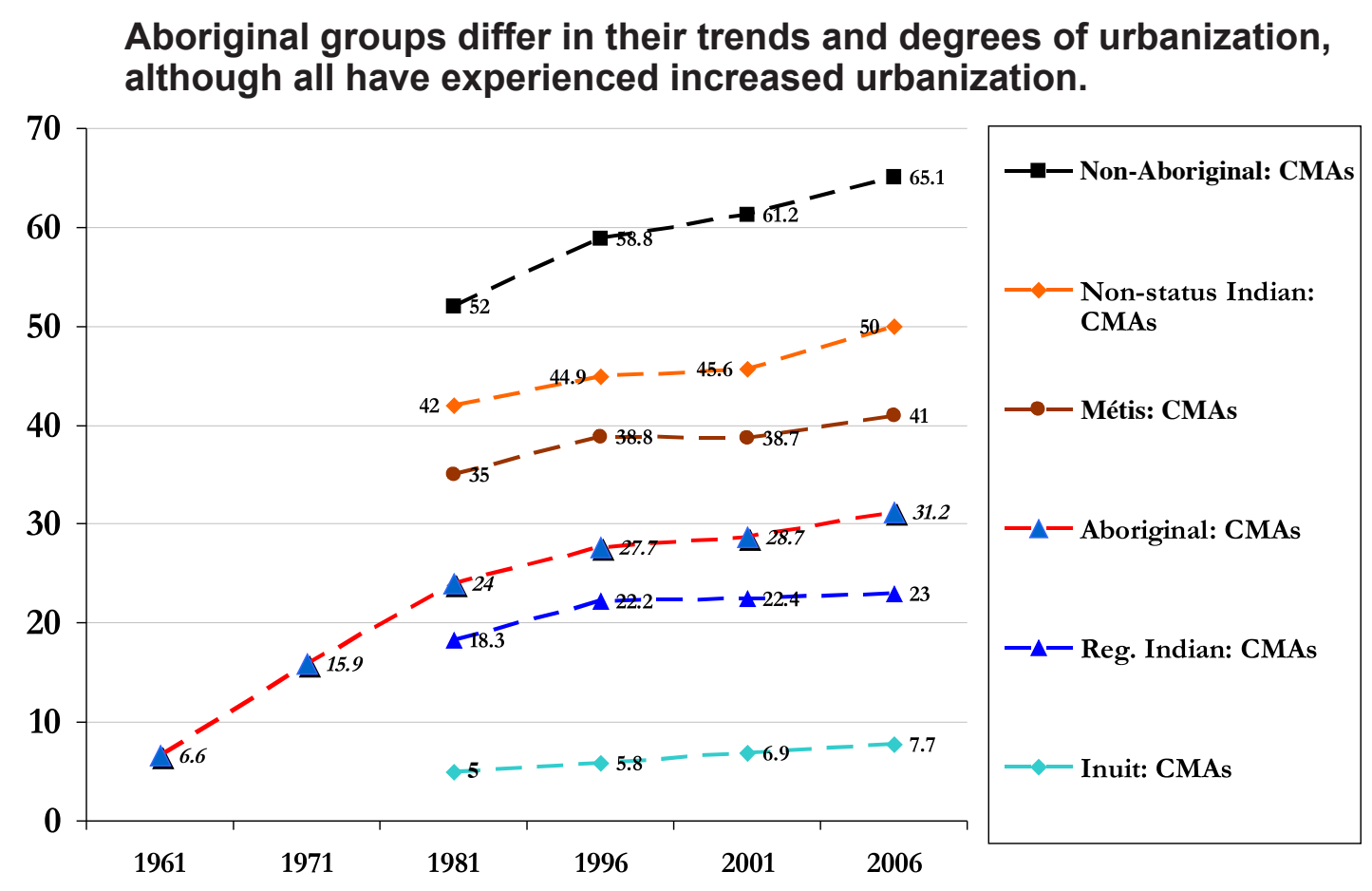

Sources: See Figure 2.

Figure 3: Percentage of Aboriginal Populations in CMAs for Selected Years, 1961-2006.

\section{Census Data Sources on Aboriginal Populations Used in This Study, 1951-2006}

Census data on Aboriginal populations in urban (City and CMA) areas were compiled from a variety of sources, many of them publications for earlier censuses, including:

- 1951, 1961, 1971 Census City data: Censuses in Perspective Canada, 1974. Catalogue No. 11-507 E, Table 12-9., p. 244; and 1951, 1961 Censuses; and Nagler, 1973, Table 1, p. 8 .

- 1971 City and CMA data: from 1971 Census of Population, Ethnic Groups, Catalogue No. 92-723. Data for cities from Table 5, pages 5-1 to 5-32; data for CMAs from Table 6, pages 6-1 to 6-8.

- 1981 Data: from 1981 Census of Population, Language, Ethnic Origin, Religion, Place of Birth, Schooling. Catalogue No. 93-929 (Vol. 2 provincial series). Data for cities from Table 2 and data for CMA/CAs from Table 3 in provincial series.

- 1981,1996, 2001 CMAs: Siggner and Costa, Statistics Canada, Census of Canada: http://www.statcan.gc.ca/pub/89-613-m/89-613-m2005008-eng.pdf; and,

- 1951, 1961, 1971, 1981 and 1991 selected cities: Peters 2000, Table 8.7, p. 247. 
All Aboriginal groups have experienced increasing urbanization, although they differ greatly in their degree of urbanization and geographic distribution. The most urbanized Aboriginal populations are Non-Status Indians, with their proportion in urban areas increasing from 70 percent in 1981 to 74 percent by 2006, and Métis, with similarly corresponding increases from 60 percent to 69 percent. In 2006, nearly one-half of Registered Indians lived on-reserve, while 40 percent lived in urban areas outside reserves: an increase from 34 percent in 1981. Although the Inuit are the least urbanized of Aboriginal people, living primarily in rural communities, they nevertheless experienced the sharpest increase in the proportion of their population residing in urban areas, going from 20 percent in 1986 to 37 percent buy 2006 (Figures 2 and 3).

Figure 4 provides a comparison of the distribution of the different Aboriginal groups, and non-Aboriginal populations among the four types of geographic areas: reserves, rural areas, urban non-CMAs, and urban CMAs. Overall, just over half of the Aboriginal Identity population resides in urban areas, with 31 percent in large urban areas (CMAs) and 22 percent in other urban, non-CMA areas. However, the four different Aboriginal populations differ significantly in their residential patterns: nearly one-half of Registered Indians live on-reserve, while most non-registered Indians (74\%) and Métis (69\%) live in cities, making them the most urbanized Aboriginal populations. Inuit are the least urbanized, living primarily in rural communities (62\%). Demographic studies on migration patterns and places of residence demonstrate that differences among Aboriginal groups in terms of location and degree of urbanization are also reflected in their mobility and migration patterns (Clatworthy and Norris 2007; unpublished paper; Norris and Clatworthy 2003). 
On Reserve

100

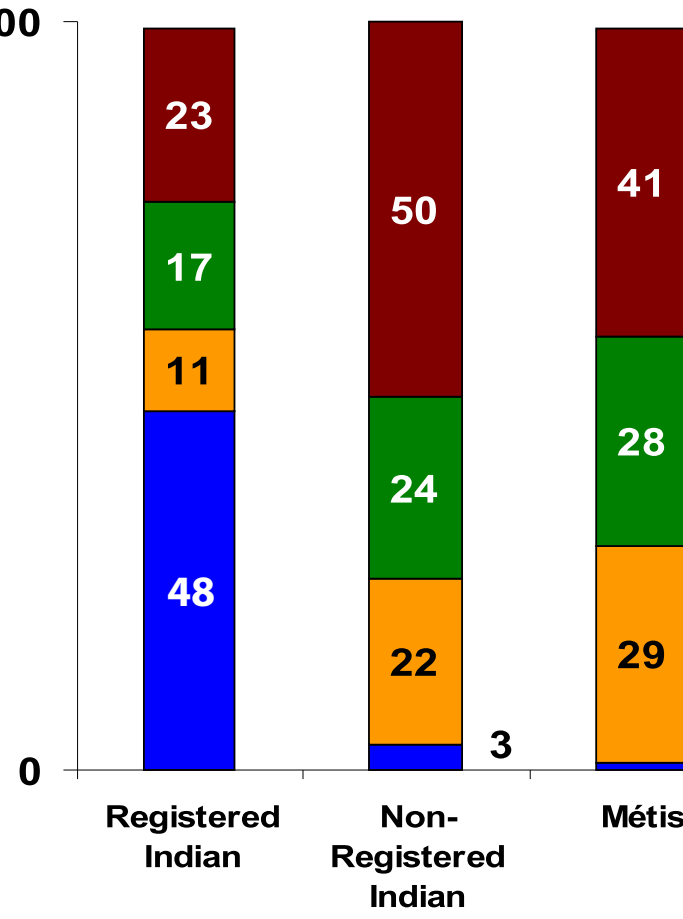

Non-CMA

CMA

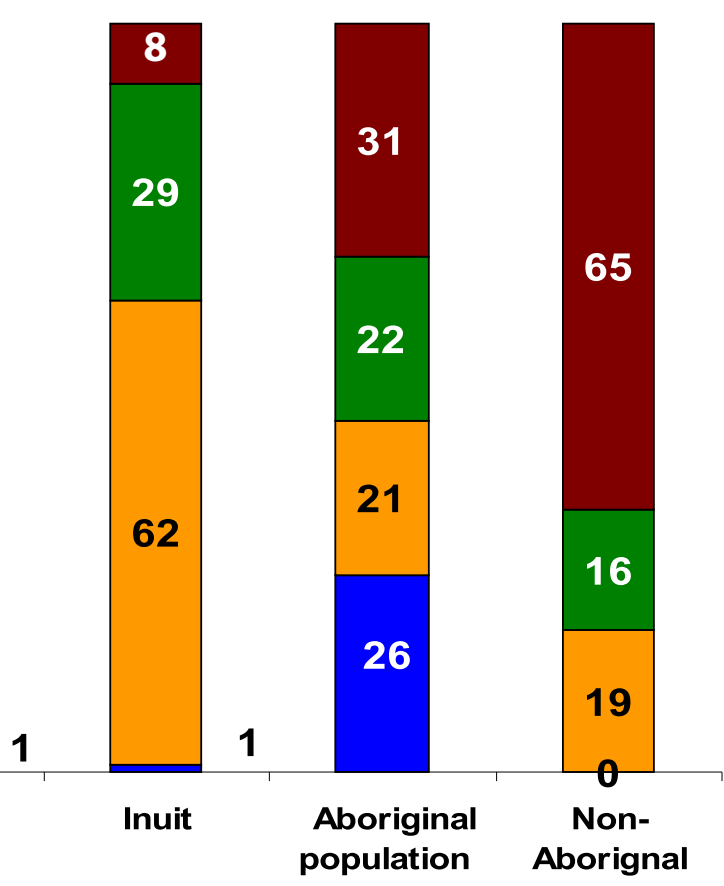

Source: Clatworthy and Norris unpublished paper. Authors' calculations come from unpublished data from Statistics Canada, 2006 Census of Canada.

Figure 4: Population Distribution of Aboriginal Identity Population by Place of Residence, Canada, 2006 Census (unadjusted).

Twelve Selected Cities: Aboriginal Population, 2006

Figure 5 shows the 2006 Aboriginal population estimates for the twelve urban areas highlighted in this study. The Aboriginal populations of these urban areas range in size from about 9,000 for Hamilton up to 68,400 for the city of Winnipeg. Collectively, these cities account for the vast majority (about 90\%) of Aboriginal residents in large urban areas. 


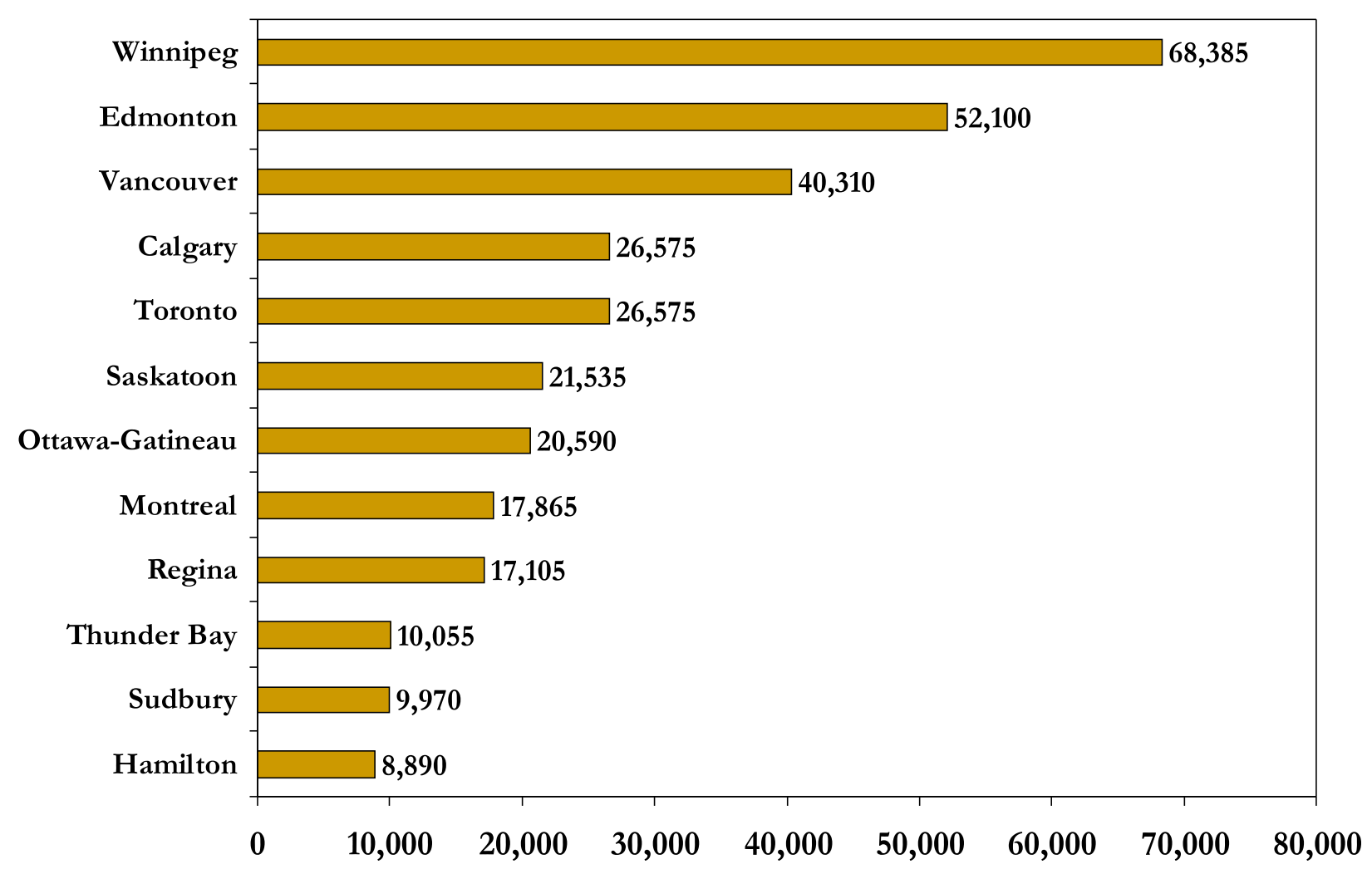

Sources: Statistics Canada, 2006 Census of Canada.

Figure 5: Twelve Canadian Cities / CMAs with Significant Aboriginal Populations in 2006

\section{Twelve Cities Combined: Aboriginal Population, 2006}

Figure 6 provides estimates of the total Aboriginal population residing in these twelve urban areas combined for the 1951 to 2006 period. Data for this period reflect ethnic origin-based Aboriginal population counts for the "City" Census Subdivision Type Classification of these urban areas, while data for 1981 to 2006 counts refer to the CMA-based classification of these urban areas. Origin-based population estimates are used for the 1971 and 1981 census years while Identity-based estimates are used for the 1996, 2001, and 2006 census years. Apart from Montreal in 1981, reserves have not been excluded from CMAs (1981 is shown twice, with and without the Kahnawake reserve).

As revealed in the figure, the combined Aboriginal population of these twelve urban areas has increased dramatically over the periods in question-more than a hundred-fold, from just 3,000 in 1951 to some 
320,000 by 2006. In fact, the Aboriginal population within these twelve urban areas overall has grown at a significantly higher rate than for groups residing outside of these major urban areas. The proportion of the total Aboriginal population residing in these twelve urban areas (Cities / CMAs) reflects this rapid growth and has increased steadily over the past fifty-five years, from just 2 percent in 1951 to 27 percent by 2006 (Figure 7).

These cities account for the vast majority

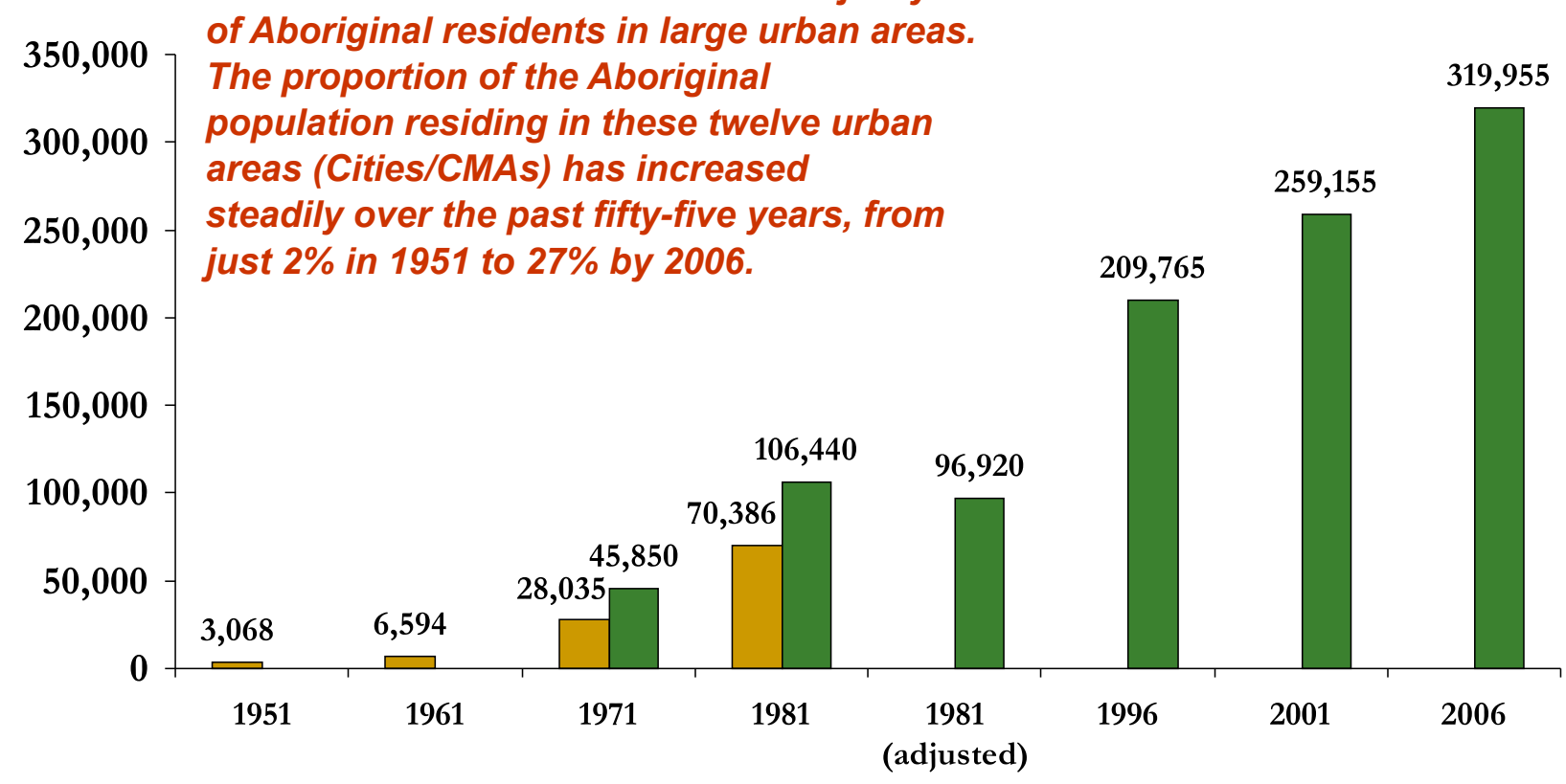

$\square$ Total of City Aboriginal Populations, 1951 to 1981

$\square$ Total of CMA Populations, 1971 to 2006

Sources: See Figure 1.

Figure 6: Total Aboriginal Population of Twelve Selected Cities and Census Metropolitan Areas, Canada, 1951 to 2006. 
The proportion of the Aboriginal population residing in these twelve urban areas (Cities/CMAs) has increased steadily over the past fifty-five years from just $2 \%$ in 1951 to $27 \%$ by 2006.

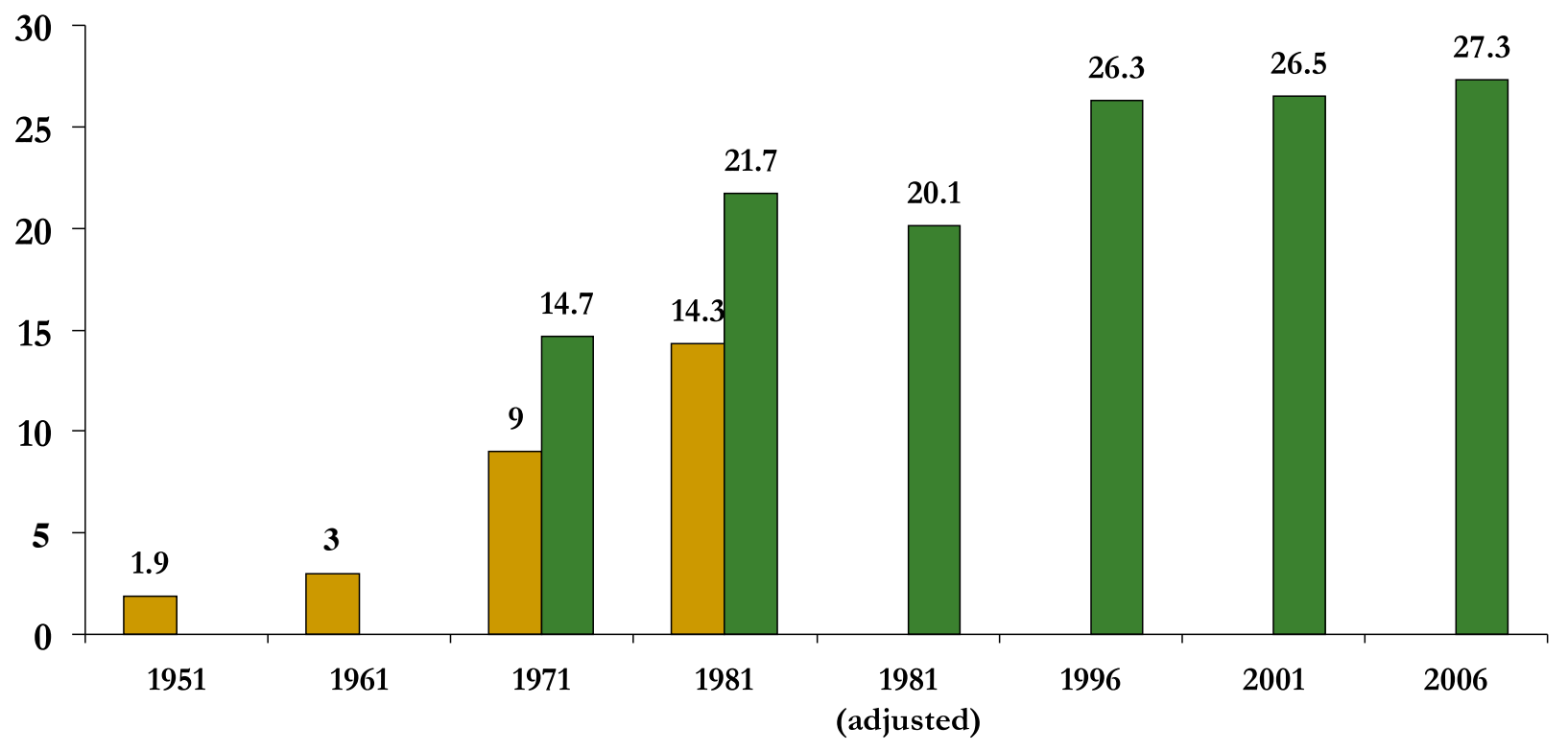

Percentage of Aboriginal Population in Twelve Cities, 1951 to 1981

Percentage of Aboriginal Population in Twelve CMAs, 1971 to 2006

Sources: See Figure 1.

Figure 7: Percentage of Total Aboriginal Residing in Twelve Selected Cities and Census Metropolitan Areas, Canada, 1951 to 2006.

The twelve selected urban areas (CMAs) represent most of the total Aboriginal population in all CMAs combined, since most-practically nine out of ten-Aboriginal residents who live in CMAs reside in these twelve particular CMAs. Since 1971, as Figure 8 illustrates, the Aboriginal population residing in these twelve CMAs combined has accounted for most of the proportion of the total Aboriginal population living in all CMAs. In 2006, for example, 27 percent of the Aboriginal population resided in these twelve CMAs alone, representing most of the 31 percent of the Aboriginal population living in all CMAs. 


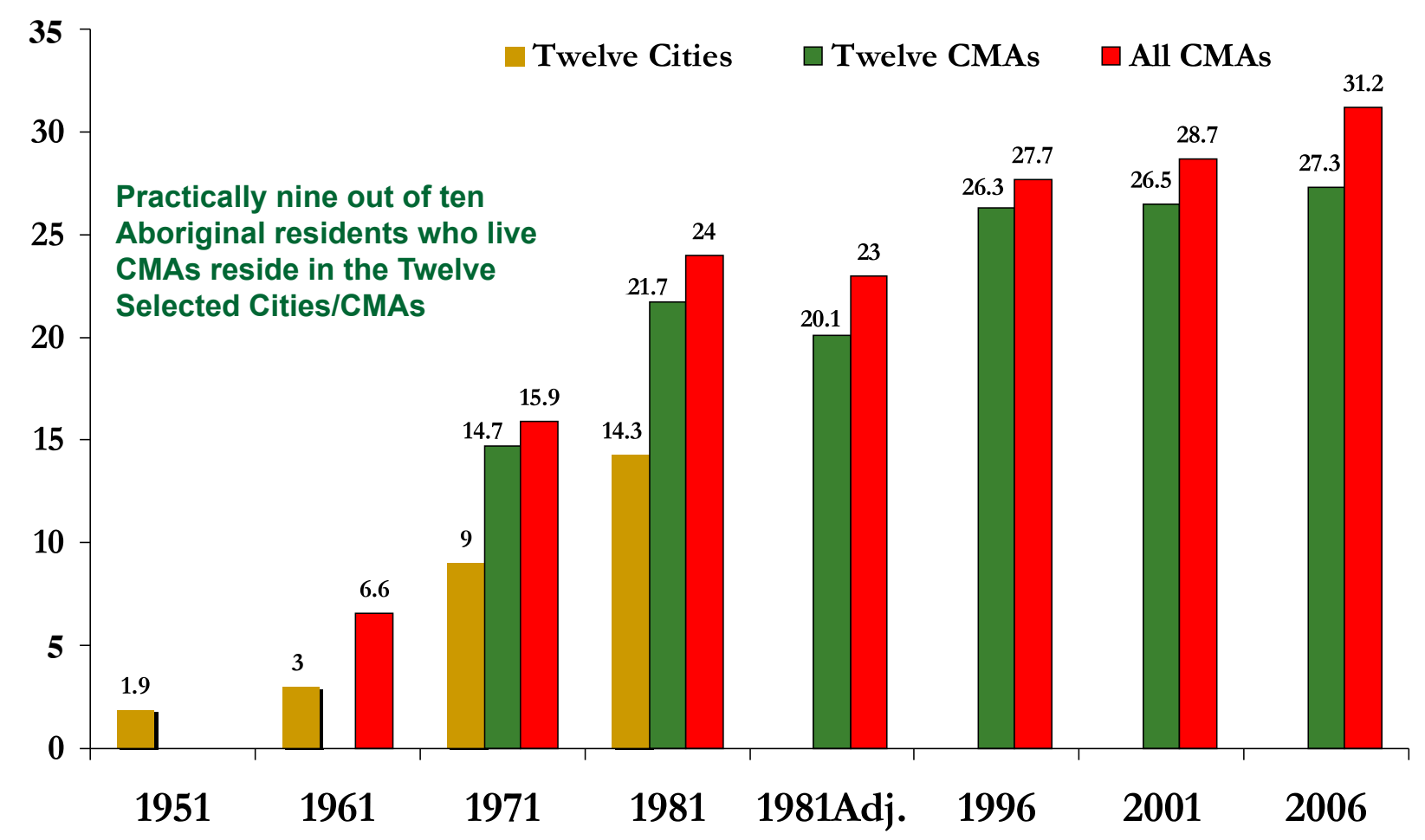

Sources: See Figure 1.

Figure 8: Percentage of Aboriginal Population Residing in Twelve Selected Cities and All Census Metropolitan Areas, Canada, 1951 to 2006.

Twelve Cities Combined: Average Annual Growth Rates over 1951 to 2006

Figure 9 shows the average annual growth rates (calculated as exponential averages $)^{4}$ of the total Aboriginal population residing in these twelve Cities/ CMAs combined for selected intercensal periods from 1951-1961 to 20012006. Growth rates of the overall Aboriginal population residing in these twelve urban areas are high at beginning with relatively small populations, but rates are still relatively high, especially over the 1981-2001 period, due to 1986-1991 impact (period not shown here) of large absolute increases in population numbers (Guimond, 2003; Peters, 2000). 
$\square$ Average Annual Growth Rate of Aboriginal Population in Twelve Cities Combined, 1951 to 1981

$\square$ Average Annual Growth Rate of Aboriginal Population in Twelve CMAs Combined, 1971 to 2006

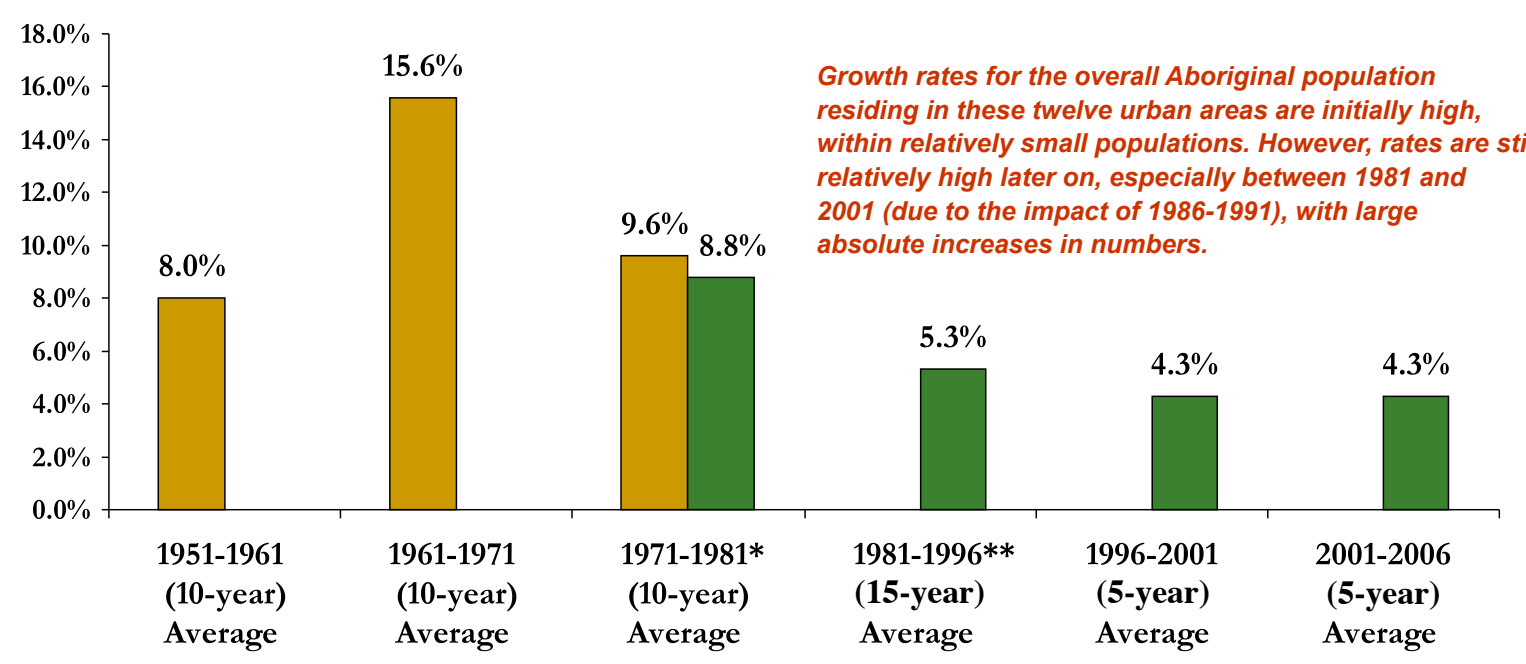

Sources: See Figure 1.

*1971-1981: Two sets of growth rates are presented for this period: one is for city-level data, the other for CMA-level data. In the calculation of these growth rates, the 1981 CMA population for Montreal includes Kahnawake.

**1981-1996: In the calculation of these growth rates, the 1981 CMA population for Montreal has been adjusted to exclude Kahnawake for comparability with the 1996 Census, in which Kahnawake is enumerated incompletely.

Figure 9: Average Annual Growth Rates of Total Aboriginal Residing in Twelve Selected Cities/ CMAs, Selected Periods 1951-1961 to 2001-2006.

Figure 10 compares the average annual rates of growth of the total Aboriginal population to those of Aboriginal populations residing within and outside of the twelve cities/ CMAs for selected intercensal periods. It shows clearly, over the 1951-1961 to 2001-2006 periods of growth, that the Aboriginal population within the twelve urban areas overall has grown at a significantly higher rate than for those residing outside of these major urban areas. For example, over the fifteen-year period between 1981 and 1996, the average annual growth rate of the total Canadian Aboriginal population was 3.4 percent. However, the Aboriginal population residing in the twelve CMAs being examined experienced higher growth, with an average annual growth rate of 5.3 percent. Conversely, the Aboriginal population outside these areas grew at a lower average annual rate of 3.7 percent. 


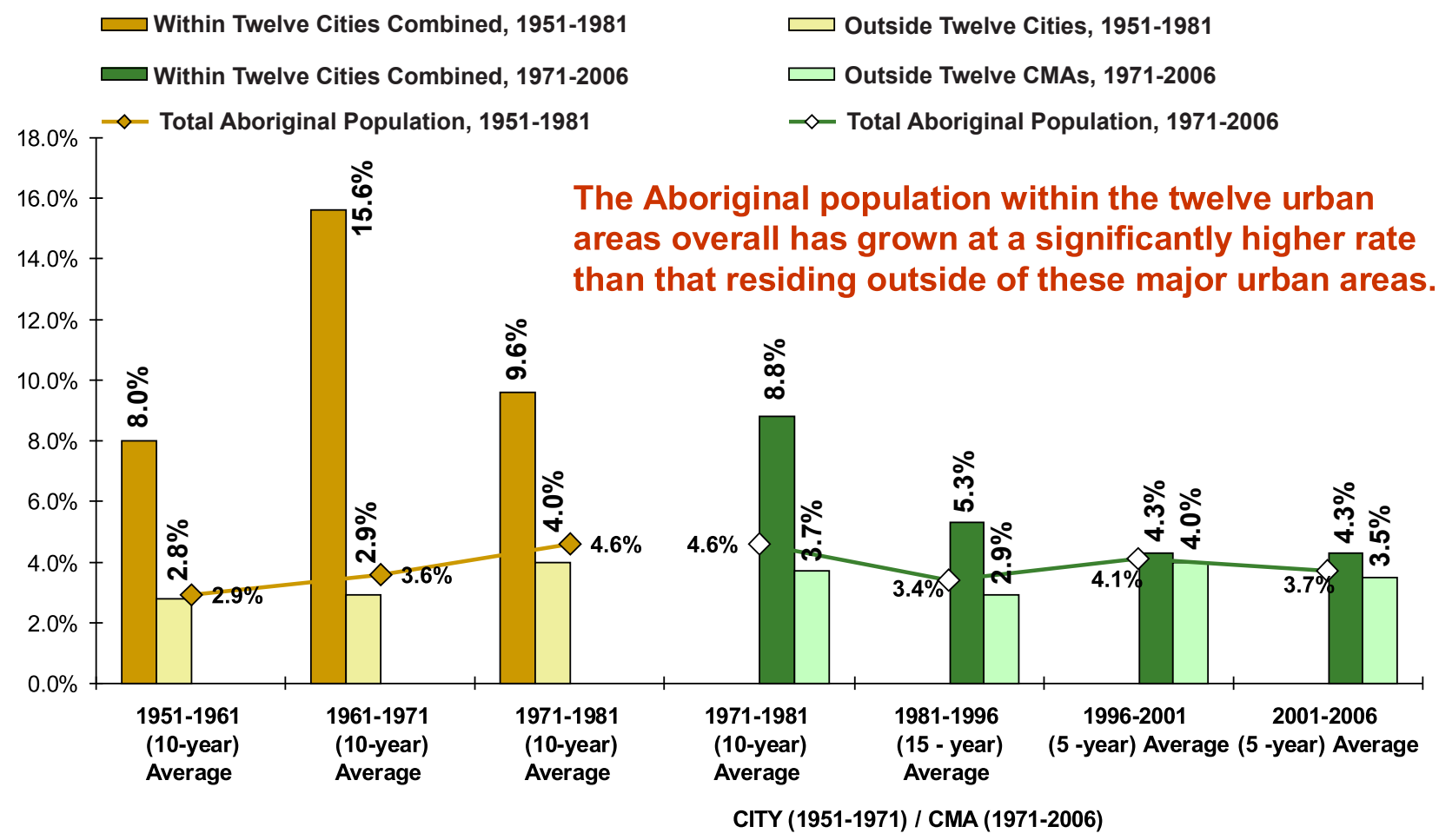

Sources: See Figure 1.

Figure 10: Average Annual Growth Rates of Total Aboriginal Populations: Total, Within and Outside Twelve Cities/ CMAs for Selected Intercensal Periods 1951-1961 to 2001-2006.

Twelve Selected Cities: Population Counts and Growth, 1951 to 2006

Canada's different urban areas vary significantly across regions in the growth patterns of their Aboriginal populations over the past fifty years. The twelvecity analysis in this section explores how Canada's cities differ in their historical patterns of Aboriginal population growth and reveals, consistent with Clatworthy's observation of urban Aboriginal growth over the decades leading up the 1980s, as noted earlier in historical trends, that while growth occurred in all regions of Canada, it was especially pronounced in Canada's western provinces and resulted in quite large Aboriginal populations in all major prairie cities (Clatworthy, 1981 from Sharzer 1985). 
Cities with 2006 Aboriginal Population of At Least 40,000

Figure 11 shows the numbers of Aboriginal people living in cities from 1951 to 2006 that had an Aboriginal Identity population of at least 40,000 in 2006. In 1951, at the beginning of the period, Aboriginal populations in each of these cities numbered only in the hundreds, yet were well into the thousands by 1981. Significant growth occurred thereafter, with large absolute increases in population counts between 1981 and 1996. For example, according to the 1981 Census, the Aboriginal origin population in the CMA of Winnipeg numbered some 16,000; in 1996 there were close to 46,000 in that city reporting an Aboriginal Identity, a number climbing to 68,400 by 2006 .

Aboriginal populations in these cities continue to grow, with fiveyear population increases over the most recent 2001- 2006 period of 23 percent in Winnipeg, 27 percent in Edmonton, and 9 percent in Vancouver. The corresponding average annual growth rates for these cities over the same five-year period are 4.2 percent , 4.9 percent and 1.8 percent respectively (Figure 12).

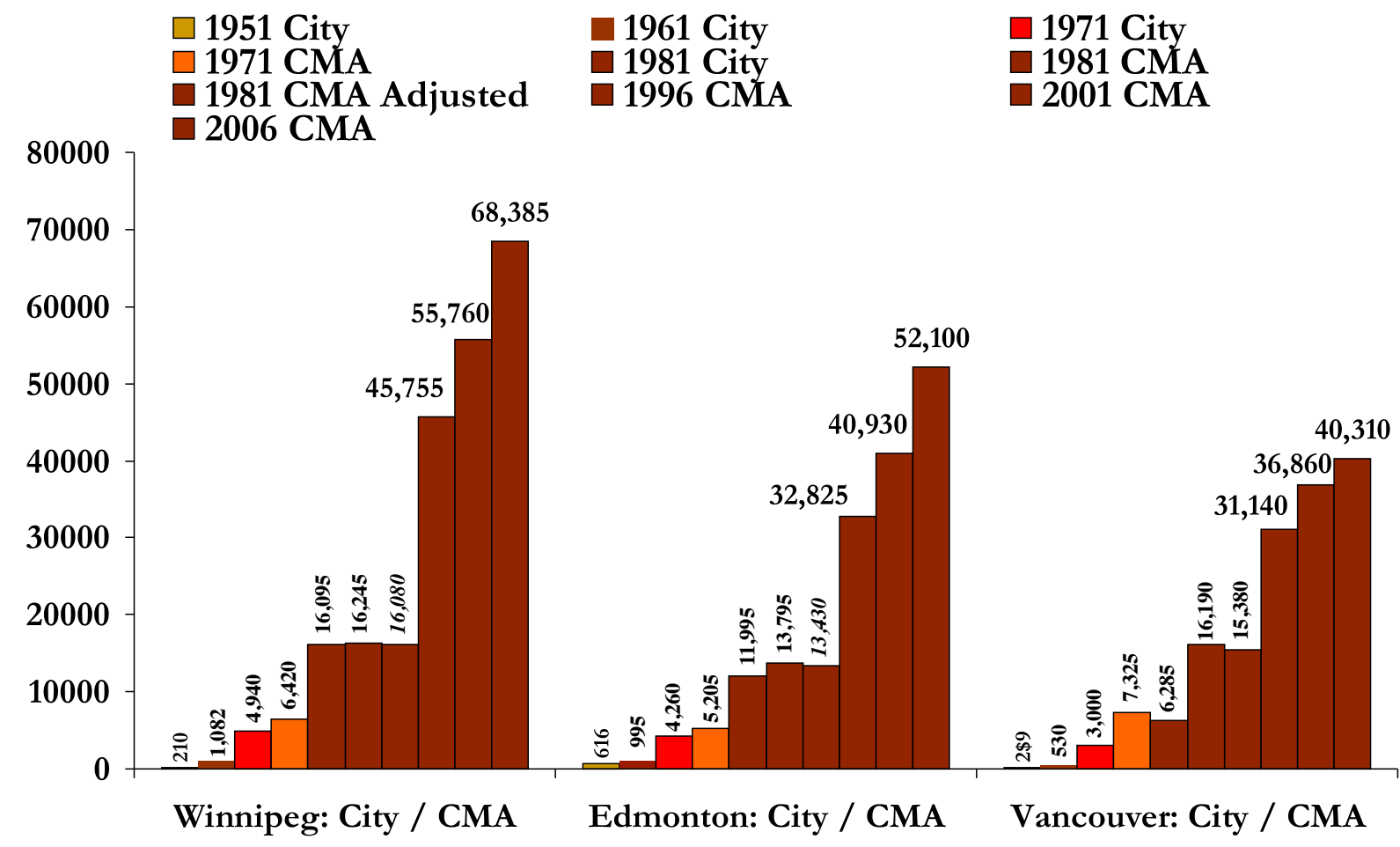

Sources: See Figure 1.

Figure 11: Aboriginal Population Counts, 1951-2006, in CMAs with an Aboriginal Identity Population of at Least 40,000 in 2006. 


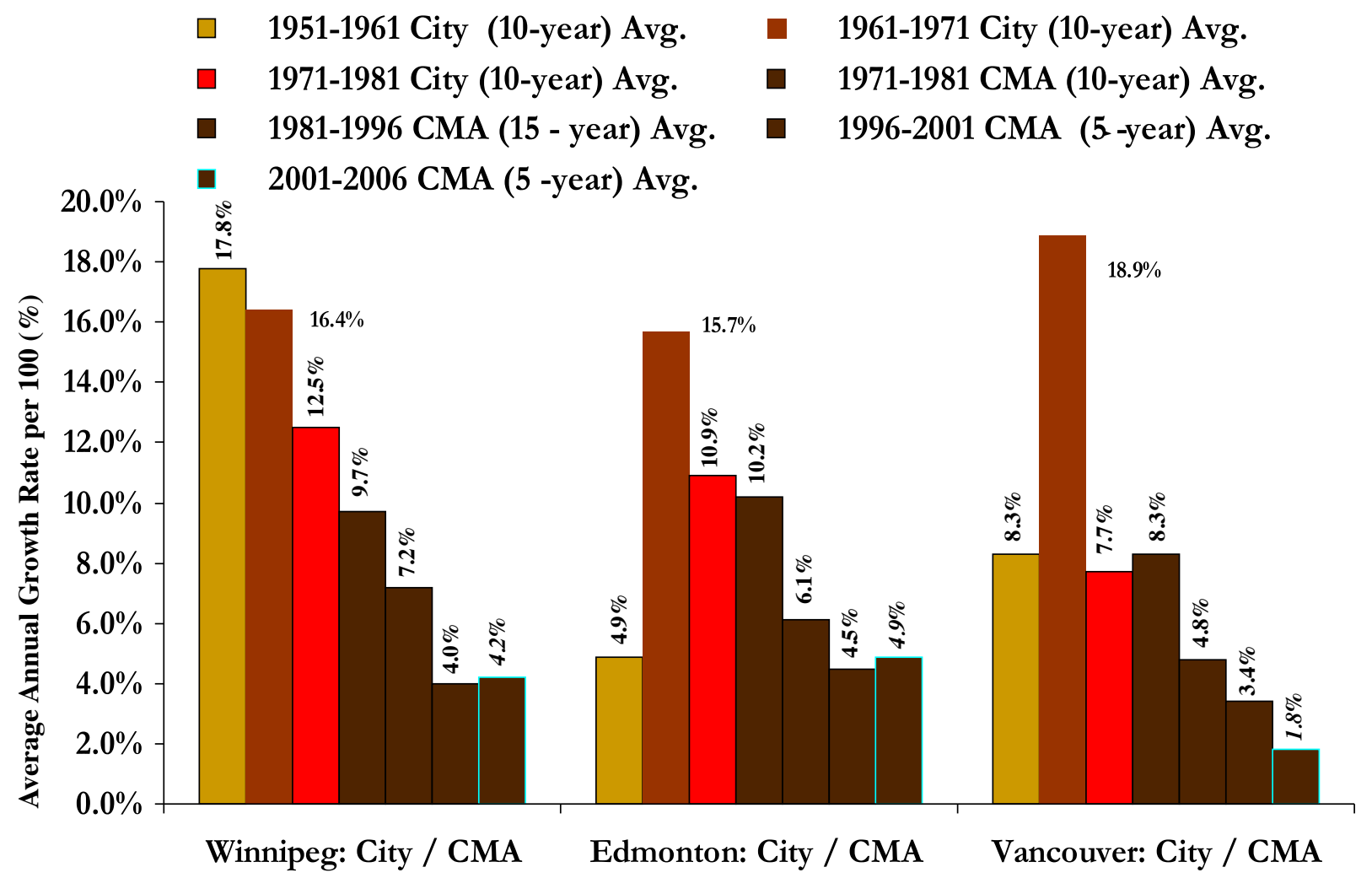

Figure 12: Average Annual Growth Rates of Aboriginal Populations for Selected Periods 1951-1961 to 2001-2006 Within CMAs with an Aboriginal Identity Population of at Least 40,000 in 2006.

Cities with 2006 Aboriginal population between 20,000 to 30,000

Figure 13 shows Aboriginal population estimates between 1951 and 2006 for the four CMAs with 2006 Aboriginal identity populations in the range of 20,000 to 30,000: Calgary, Toronto, Saskatoon, and Ottawa/Gatineau.

At the beginning of 1951, Aboriginal populations in three of these cities numbered less than a hundred, while Toronto had 880. By 1981, populations were into the thousands, with significant increases in numbers for later periods and for Saskatoon especially between 1981 and 1996. In the CMA of Saskatoon, the Aboriginal population climbed from less than a hundred in 1951 to some 4,000 by 1981, reaching 16,000 in 1996, and coming close to 22,000 by 2006 . Calgary and Toronto have Aboriginal populations of similar size - about 27,000 - and also appear to share similar patterns of past growth. 
While Saskatoon and Ottawa-Gatineau also have Aboriginal populations of similar size to each other-about 21,000 - their patterns of growth tend to differ. Saskatoon saw its greatest increases in numbers over the 1981-1996 period, whereas Ottawa/Gatineau saw significant population increases over the more recent 2001-2006 period, as well as during the earlier period between 1981 and 1996.

Aboriginal populations in these cities continue to grow, with population increases and corresponding average annual growth rates between 2001 and 2006 ranging from a 6 percent increase and average annual growth rate of 1.2 percent in Saskatoon, to a notable 53 percent increase, and annual growth of 8.8 percent in Ottawa/Gatineau. Meanwhile, Calgary and Toronto experienced five-year increases of 21 percent and 31 percent respectively, with corresponding average annual growth rates of 3.9 percent and 5.5 percent (Figure 14).

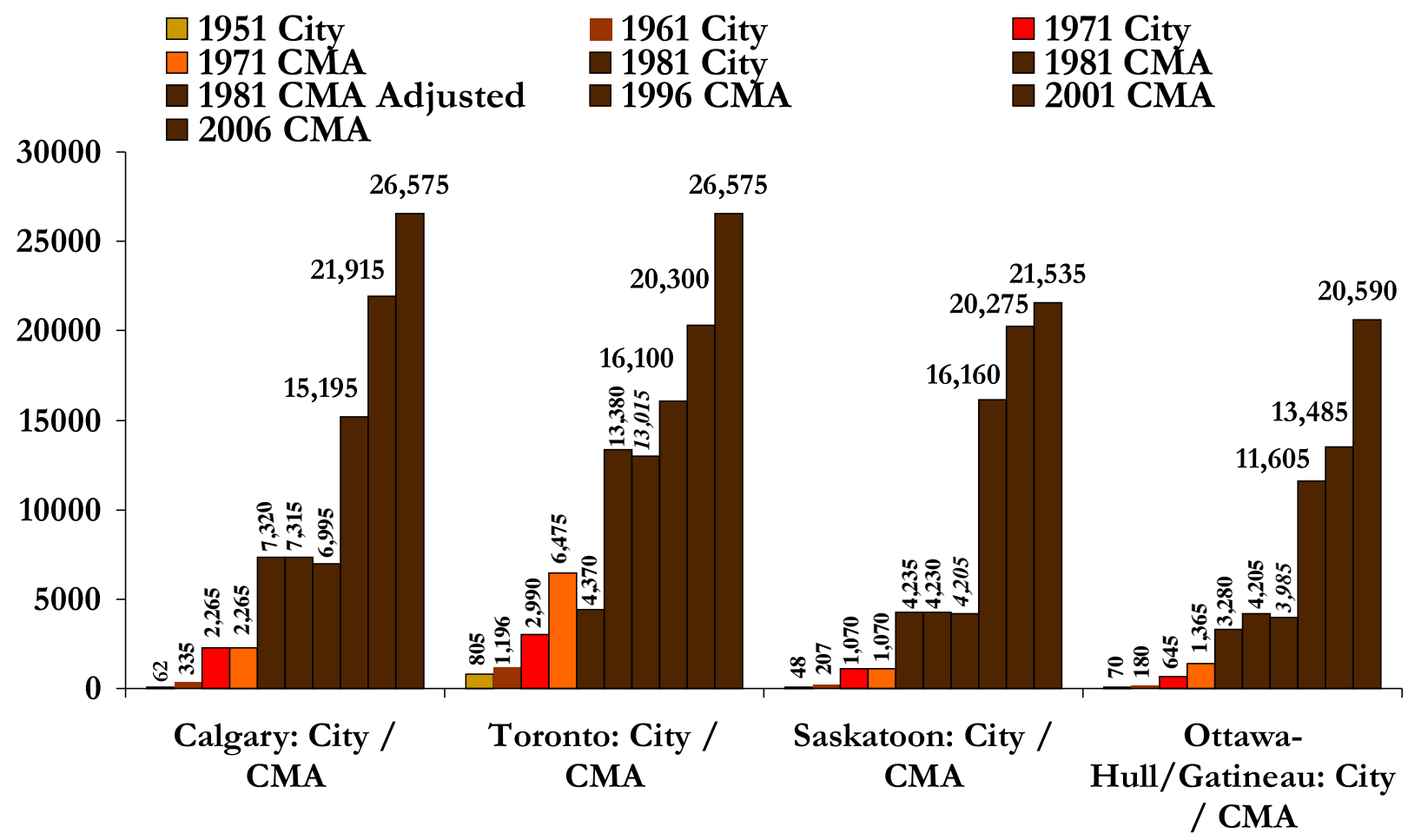

Sources: See Figure 1.

Figure 13: Aboriginal Population Counts, 1951 to 2006, in CMAs with an Aboriginal Identity Population between 20,000 to 30,000 in 2006 . 


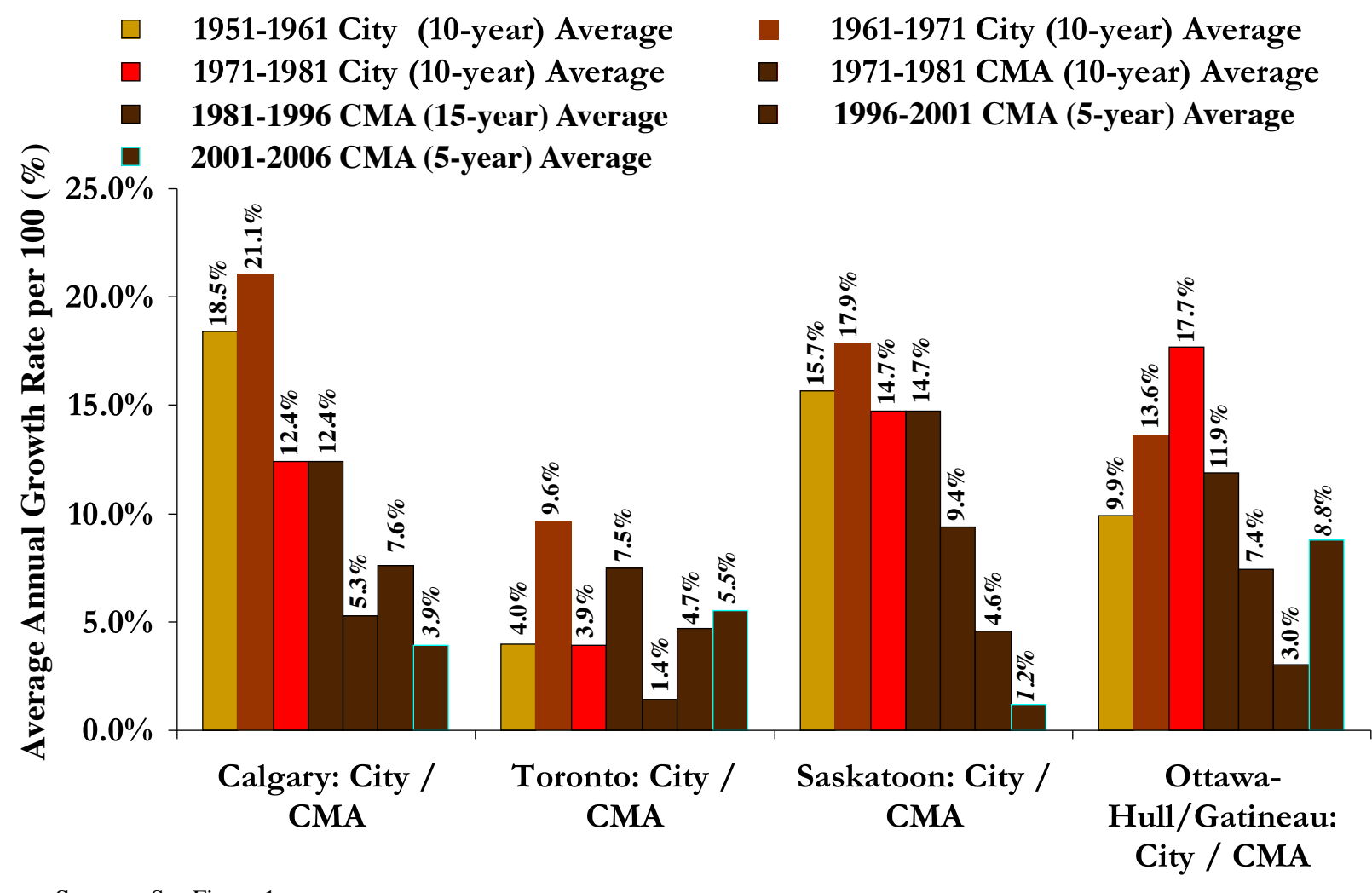

Sources: See Figure 1.

Figure 14: Average Annual Growth Rates of Aboriginal Populations for Selected Periods 1951-1961 to 2001-2006 Within CMAs with an Aboriginal Identity Population between 20,000 to 30,000 in 2006.

Cities with 2006 Aboriginal population 8,000 to less than 20,000

Figure 15 shows Aboriginal population counts from 1951 to 2006 for the remaining five of the twelve CMAs with 2006 Aboriginal identity populations in the range of at least 8,000 and less than 20,000: Montreal, Regina, Thunder Bay, Sudbury, and Hamilton. At the beginning of 1951, Aboriginal populations in each of these cities generally numbered in the hundreds and were also into the thousands by 1981, with continued growth over later periods. Over the period from 1981 to 1996, Aboriginal populations, especially in Regina and to some extent Thunder Bay, saw significant increases in their absolute numbers.

While Montreal and Regina have Aboriginal populations of similar size-about 17,000 to 18,000 -their patterns of growth tend to differ. Regina saw sharp increases in numbers over the 1981-1996 period, whereas 
Montreal saw significant population increases more over the most recent 2001-2006 period.

Also, while the three Ontario cities of Thunder Bay, Sudbury, and Hamilton have Aboriginal populations of similar size, of 9,000 to 10,000, growth patterns were not the same: Hamilton did not post the same sharp increase over the 1981-1996 period.

Aboriginal populations in these cities continued to show significant growth over the 2001-2006 period. Montreal especially saw a 61 percent increase in population, and an average annual growth rate of 10 percent over the five-year period. It was followed by Sudbury, Thunder Bay, and Hamilton, with five-year increases of 35 percent, 23 percent, and 22 percent respectively, and corresponding respective annual growth rates of 6.2 percent, 4.2 percent, and 4.1 percent. Regina experienced the lowest increase and average annual growth rate of just 9 percent and 1.7 percent, respectively (Figure 16).

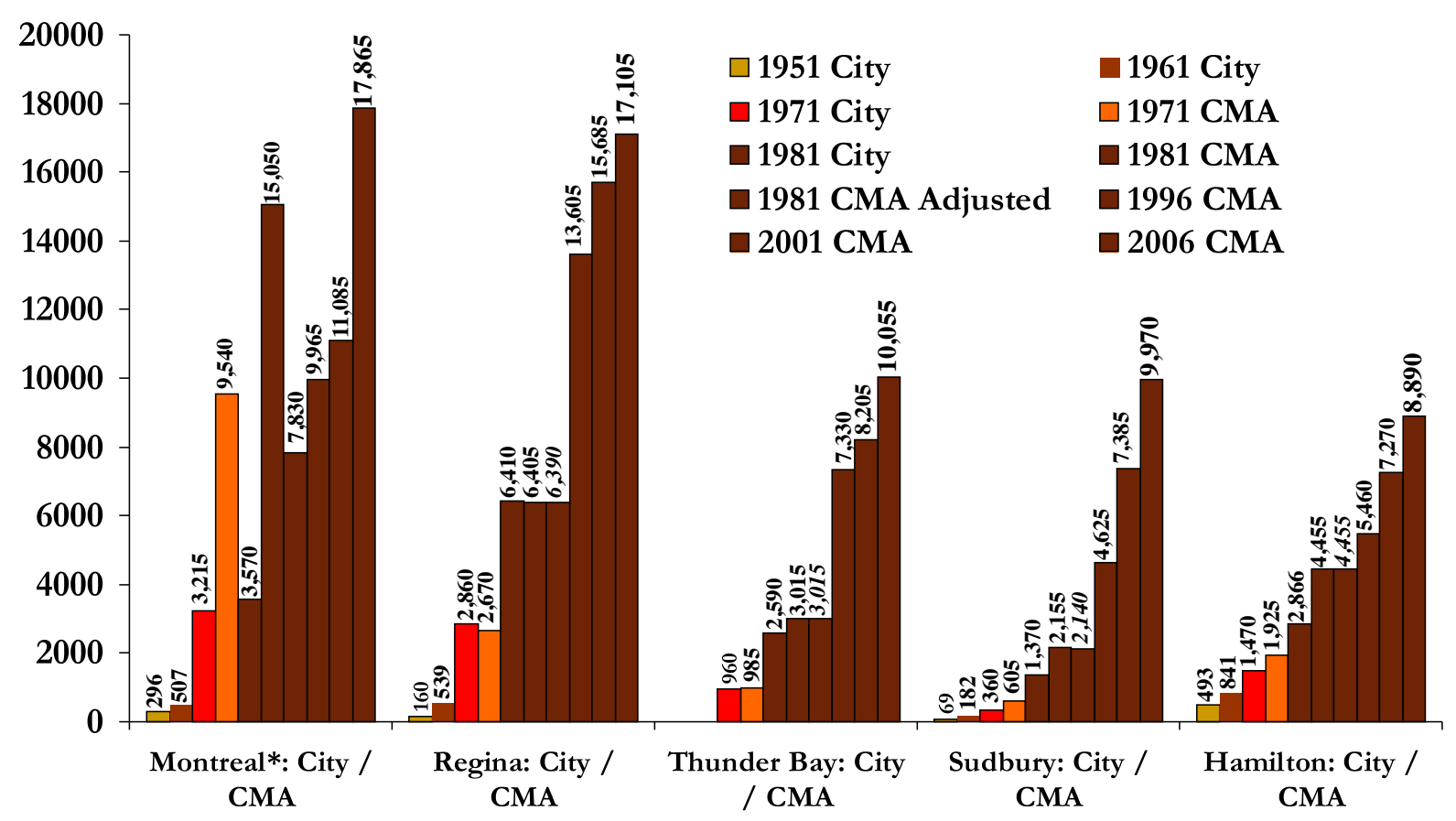

*Montreal CMA: 1971 and 1981 Censuses include Kahnawake; 1981 Adjusted does not include Kahnawake. Enumeration of Kahnawake for the 1996 to 2006 Censuses was imcomplete, and the CMA therefore does not include the reserve population.

Figure 15: Aboriginal Population Counts, 1951 -2006, in CMAs with a 2006 Aboriginal Identity Population at least 8,000 and less than 20,000. 


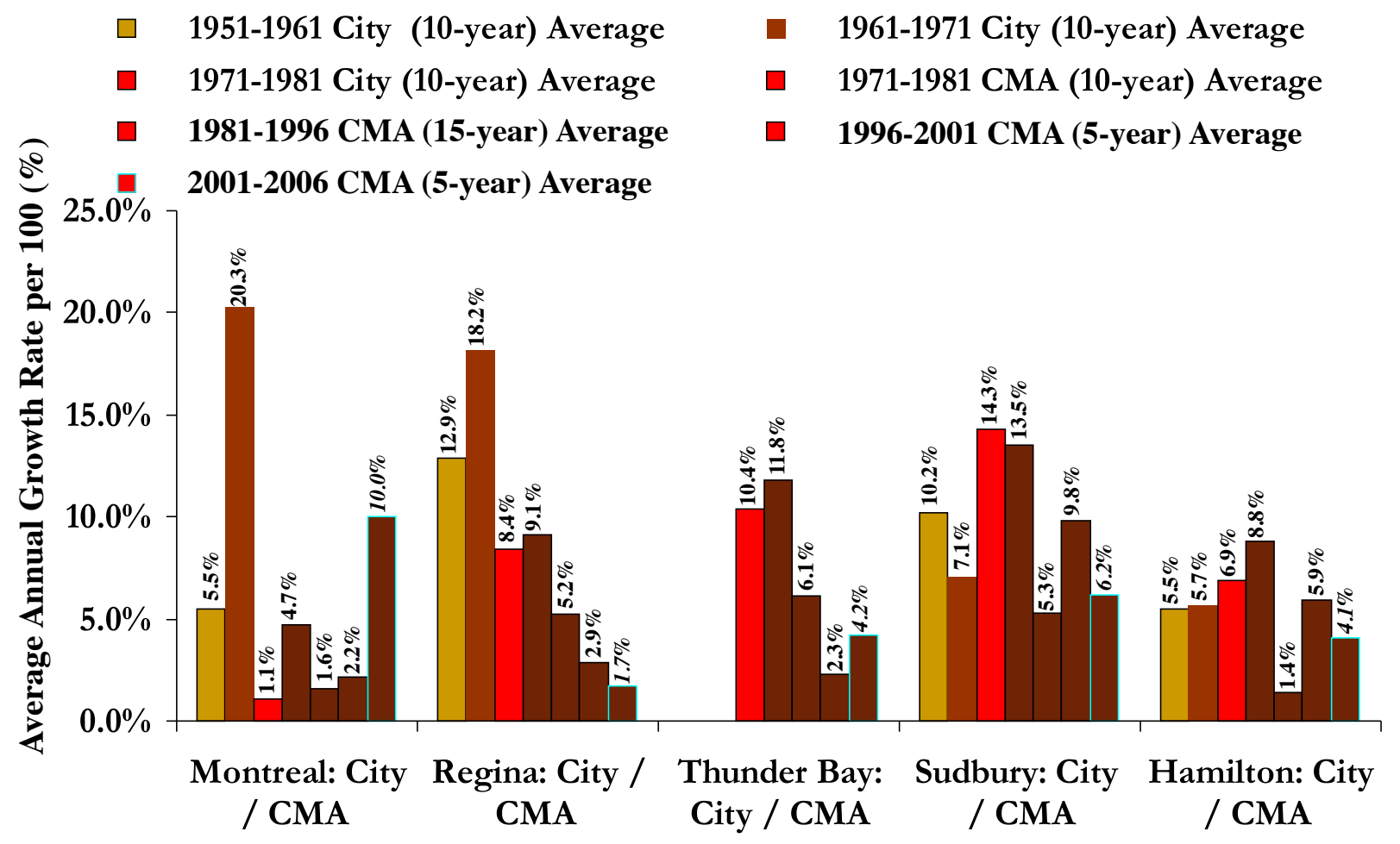

Figure 16: Average Annual Growth Rates of Aboriginal Populations for Selected Periods 1951-1961 to 2001-2006 within CMAs with 2006 Aboriginal Identity Population at least 8,000 and less than 20,000 .

\section{Migration as a Factor in the Urbanization of Aboriginal Populations}

The considerable growth of Aboriginal populations that has been observed over the past half century in both urban areas in general and individual cities brings us to the subject of contributors to urban growth. Turning to migration as a factor in the urbanization of Aboriginal populations, we ask the question: To what extent has migration contributed to the rapid increase in the Aboriginal population living in major urban areas?

\section{Patterns and Trends in Aboriginal and Non-Aboriginal Migration}

Census-based research has shown that the mobility and migration rates of Aboriginal populations, especially Registered Indians, have consistently been much higher than those of non-Aboriginal residents in Canada's urban areas. This higher mobility of Aboriginal people, as compared to non- 
Aboriginal people, reflects not only migration to/from reserves and cities, but also high levels of residential mobility (Clatworthy and Norris 2007; unpublished paper; Norris et al. 2003).

As well, patterns of Registered Indian migration differ from those of other Aboriginal groups in the movement of that population to and from reserves. In general, other (i.e., non-Registered) Aboriginal groups tend to be more mobile compared to the mainstream population and Registered Indians overall. However, in non-reserve areas, Registered Indian residents, especially those in urban areas, display higher rates of mobility than their counterparts on-reserve and other Aboriginal groups living off-reserve, as well as the general Canadian population: a pattern that has been consistently documented since the early 1970s (Clatworthy and Norris 2007; Norris et al. 2003 b; Siggner 1977; Norris 1985). With respect to migration patterns (or moves from one community to another), it is the movement to and from reserves that distinguishes Registered Indians from other Aboriginal groups. Migration is a reciprocal process - in their roles as both origins and destinations, reserves serve to increase the "churn" to and from cities to such an extent that the Registered Indian population tends to be more mobile than other Aboriginal groups in urban areas.

Historical analyses reveal that high levels of Aboriginal mobility and migration have persisted over long periods of time; however, recent data from the 2001 and 2006 censuses suggest that the mobility and migration rates of Aboriginal populations have started to decline. In relation to earlier time periods, the volume of both Aboriginal mobility and migration observed for the 1996-2006 period was lower. Additionally, five-year migration rates during the 2001-2006 period for both Registered Indians and Inuit fell below that of the non-Aboriginal population in all locations except in urban areas (Clatworthy and Norris, unpublished paper). Analyses of recent (post-1991) trends suggest that, although the mobility rates of Aboriginal populations remain higher than that of non-Aboriginal populations in urban areas, levels of mobility and migration among the Aboriginal and nonAboriginal populations are converging.

\section{Registered Indian Migration: Long-term Patterns and Trends}

Due to changes in census population definitions, long-term migration trends are available only for the Registered Indian population. Figure 17 provides trends in Registered Indian five-year migration, based on average annual net 
migration rates by place of residence (on reserve, rural, urban non-CMAs, and urban CMAs) from 1966-1971 to 2001-2006.

Net inflows of Registered Indian migrants to reserves, first reported for the 1966-1971 time period by Siggner (1977), have continued throughout the past thirty-five-year period. Trends indicate a continuation of longterm patterns with net inflows of Registered Indian migrants to reserves, although those would be relatively small in relation to reserve populations, and net out-migration of Registered Indians from rural areas and smaller urban areas.

However, a more complex trend of net migration exists for the larger urban areas (CMAs). As revealed in Figure 17, large urban centres recorded net inflows of migrants throughout most of the 1966-1991 time period most significantly, the largest impact of net in-migration to urban CMAs occurred during 1966-71, when net in-migration played an important role in the process of Aboriginal urbanization. Thereafter, the role of migration as a factor in urban Aboriginal population change has been greatly reduced and variable in direction. Net outflows of Aboriginal migrants were recorded during the 1976-1981 period and the period spanning 1991-2001. Relatively small net inflows of Aboriginal migrants to large urban areas were observed for the 1981-1991 period and for the most recent period, 2001-2006.

While major focal points in Registered Indian migration continue to be urban areas and reserves, the impact of net migration has been felt most significantly in rural areas, which have lost population through migration mainly to urban areas. The more recent impact of net migration on urban areas, whether positive or negative, is small relative to the size of the Registered Indian population in urban areas. 


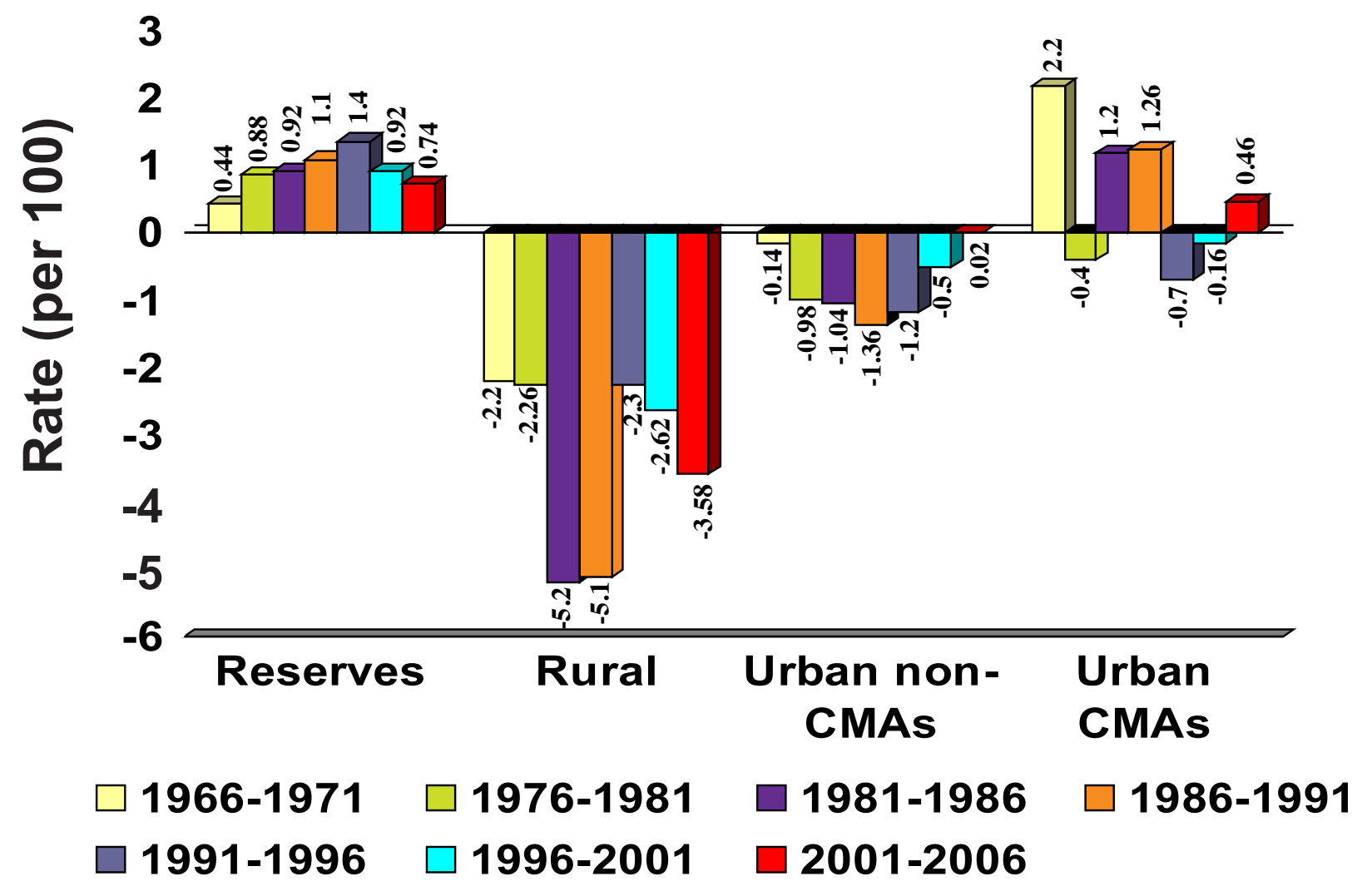

Sources: Clatworthy and Norris 2007; unpublished paper; Norris et al. 2004.

Figure 17: Trends in Registered Indian Average Annual Net Migration Rates by Location, Canada, 1966-1971 to 2001-2006.

Migration as a Factor of Urban Growth at the Beginning Period of Urbanization

It would appear, from both the literature and the census-based analysis, that migration as component of growth contributed to the beginning period of Aboriginal urbanization, declining thereafter. With respect to the growth of urban Aboriginal populations starting in the early decades after 1951, many observers attributed the substantial increases in Indian population over 1951-1961 and 1961-1971 periods to migration; as Nagler $(1973,7)$ observed, "Clearly, the vast increases in the urban Indian population cannot be attributed to any other factor than migration from reserve areas." 
Census-based analysis would also suggest that migration contributed to the growth of the Aboriginal population in urban areas during the beginning periods of urbanization, with migration accounting for roughly one quarter of growth of Registered Indian population in large urban areas. While not directly comparable, the size and direction of census-based on/off-reserve migration of band (Registered) Indians over the 1966-1971 period appears to be consistent with the average growth of the Indian population observed in the twelve urban areas over the time between 1961 and 1971. A crude estimate-based analysis suggests that the net in-migration of band Indians to urban CMAs could yield an net inflow of roughly about 2500 migrants over five years, or 500 annually (based on Siggner 1977). Between 1961 and 1971, the twelve urban areas combined saw an increase in Aboriginal (Indian) population of about 21,000 over that ten year period, or 2,100 annually. Assuming the 1966-1971 direction and levels of net in -migration represent a continuation of the previous five-year period of 1961-1966 (migration data not available), then the estimated average annual gain of 500 migrants to urban areas would account for about a quarter of the average annual population increase of 2100 , roughly, on an annual basis.

\section{Migration as a Factor of Urban Growth over the 1986-1996 Period of Urbanization}

While migration was a major factor at beginning period of Aboriginal urbanization, its impact on urbanization clearly diminished over later periods, with large urban areas experiencing either small net inflows or net out-flows of migrants. Table 1 provides data on the counts of the total ${ }^{5}$ Aboriginal population for CMAs as a whole (excluding Indian reserves) and net in/out migration levels by location of residence (urban CMAs, urban non-CMAs, rural areas, and reserves), for the two intercensal periods of 1986-1991 and 1991-1996. The comparison for the Aboriginal population overall suggests that migration does not appear to be a major growth factor in large urban areas, even in the case of net in-migration. Although there was a net inflow of migrants to large metropolitan areas over the 19861991 period $(+5,550)$, it accounted for just 7 percent of the observed growth $(75,295)$ in urban areas between 1986 and 1991 (Guimond 2003). And, in contrast to the large absolute increases in numbers of Aboriginal people in all urban areas (CMA and non-CMA combined) over 1986-1991, the period of 1991-96 saw an overall net loss of migrants $(-2,865 ;-12,420)$, indicating more Aboriginal people left than moved to urban areas (Table 1). 
- In contrast to the large absolute increases in numbers of Aboriginal people in urban areas over 1986 -1991, an overall net loss of migrants $(-2,865$, $-12,420)$ occurred between 1991and1996, indicating more Aboriginal people left urban areas than moved to them.

-Although there was a net inflow of migrants to large metropolitan areas over the 1986-1991 period $(+5,550)$, it accounted for just $7 \%$ of the observed growth $(75,295)$ in urban areas between 1986 and

\begin{tabular}{|c|c|c|c|c|}
\hline \multicolumn{3}{|c|}{ Census Years } & \multicolumn{2}{|c|}{ Intercensal Period } \\
\hline $1986^{*}$ & $1991^{*}$ & $1996^{*}$ & $1986-1991$ & $1991-1996 *$ \\
\hline \multicolumn{5}{|c|}{ Aboriginal Population in CMAs* (excluding Indian reserves) } \\
\hline 192,285 & 267,580 & 337,900 & 75,295 & 70,320 \\
\hline \multicolumn{5}{|c|}{ Net In / Out Migration of Aboriginal Population by Location } \\
\hline \multicolumn{3}{|c|}{ Urban CMAs } & $+5,540$ & $-6,150$ \\
\hline \multicolumn{3}{|c|}{ Urban Non CMA Areas } & -8405 & $-6,270$ \\
\hline \multicolumn{3}{|c|}{ Rural Areas } & $-6,675$ & +205 \\
\hline \multicolumn{3}{|c|}{ Reserves } & $+9,504$ & $+12,215$ \\
\hline \multicolumn{5}{|c|}{$\begin{array}{l}\text { Sources: Guimond 2003a; 2003b; Clatworthy 1994; Norris and Clatworthy 2003; Norris and } \\
\text { Beavon } 2000 \text { (WIRA). } \\
\text { Popplation estimates besed on percentage urban (41\%) and } 1996 \text { (47\%) in Guimond 2003a; } \\
1986-1991 \text { increases in urban population in Guimond } 2003 \text { b (yielding 43\% urban in 1991). }\end{array}$} \\
\hline
\end{tabular}
1991 (Guimond 2003).

Table 1: Migration as a Factor of Growth of Urban Aboriginal Identity Population over 1986-1996 periods.

Migration as a Factor of Urban Growth over the 1996-2006 Period of Urbanization

As a factor of growth, migration remained marginal in the observed growth of Aboriginal Identity population living in CMAs over the 1996-2006 period. As in the two previous intercensal periods of 1986-1991 and 1991-1996, migration was not a major factor in the growth of the urban Aboriginal population over the more recent 1996-2001 and 2001- 2006 periods. Again, as illustrated in Table 2, even with a net inflow of migrants to urban areas, the impact of migration in relation to population growth is minimal. Between 2001 and 2006, the net migration of +3,570 Aboriginal people to CMAs represents only 4 percent of the observed growth $(86,290)$ of the Aboriginal Identity population over 2001-2006. 


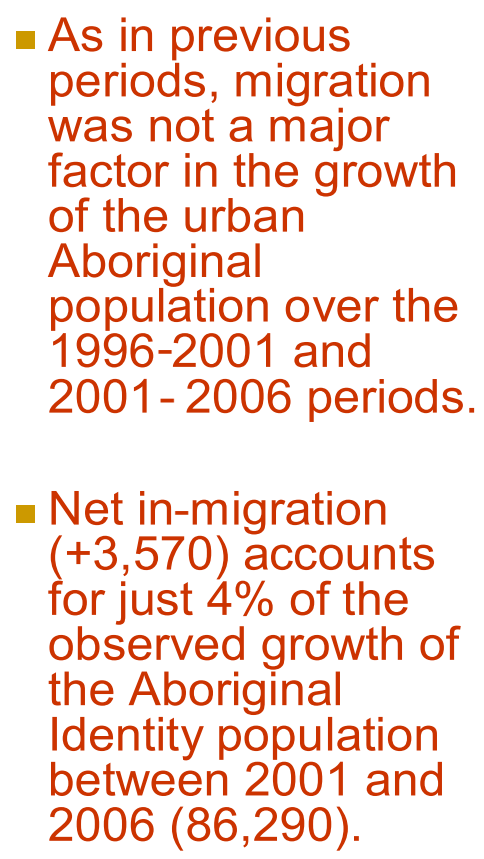

\begin{tabular}{|c|c|c|c|c|}
\hline \multicolumn{3}{|c|}{ Census Years } & \multicolumn{2}{|c|}{ Intercensal Period } \\
\hline 1996 & 2001 & 2006 & 1996-2001 & 2001-2006 \\
\hline \multicolumn{5}{|c|}{ Aboriginal Population in CMAs* (excluding Indian reserves) } \\
\hline 221,295 & 279,875 & 366,165 & 58,580 & 86,290 \\
\hline \multicolumn{5}{|c|}{ Net In / Out Migration of Aboriginal Population by Location } \\
\hline \multicolumn{3}{|c|}{ Urban CMAs } & -430 & $+3,570$ \\
\hline \multicolumn{3}{|c|}{ Urban Non-CMA Areas } & $-4,095$ & -135 \\
\hline \multicolumn{3}{|c|}{ Rural Areas } & $-6,430$ & $-13,350$ \\
\hline \multicolumn{3}{|c|}{ Reserves } & $+10,995$ & $+10,995$ \\
\hline
\end{tabular}

Table 2: Migration as a Factor of Growth of Urban Aboriginal Identity Population over 1996-2006 periods.

\section{Aboriginal Migration: Population Turnover,Loss, and Gain,in Selected CMAs}

As noted earlier, gross migration rates, the sum of in-plus-out rates to an area, provide some indication of the amount of turnover, or "churn," in the urban Aboriginal population. Movement to and from large urban areas is a significant component of Aboriginal migration: this "churn effect" is quite large among Aboriginal populations in CMAs. As Figure 18 indicates for selected CMAs over the 1996-2001 migration period, Aboriginal residents experienced significantly higher rates of in- and out-migration as compared to non-Aboriginal residents. For example, in cities with large Aboriginal populations, Aboriginal migration rates, ranging from 54.0 per 1,000 population in Winnipeg to 92.4 in Saskatoon, exceed those of the nonAboriginal population by a wide margin. 


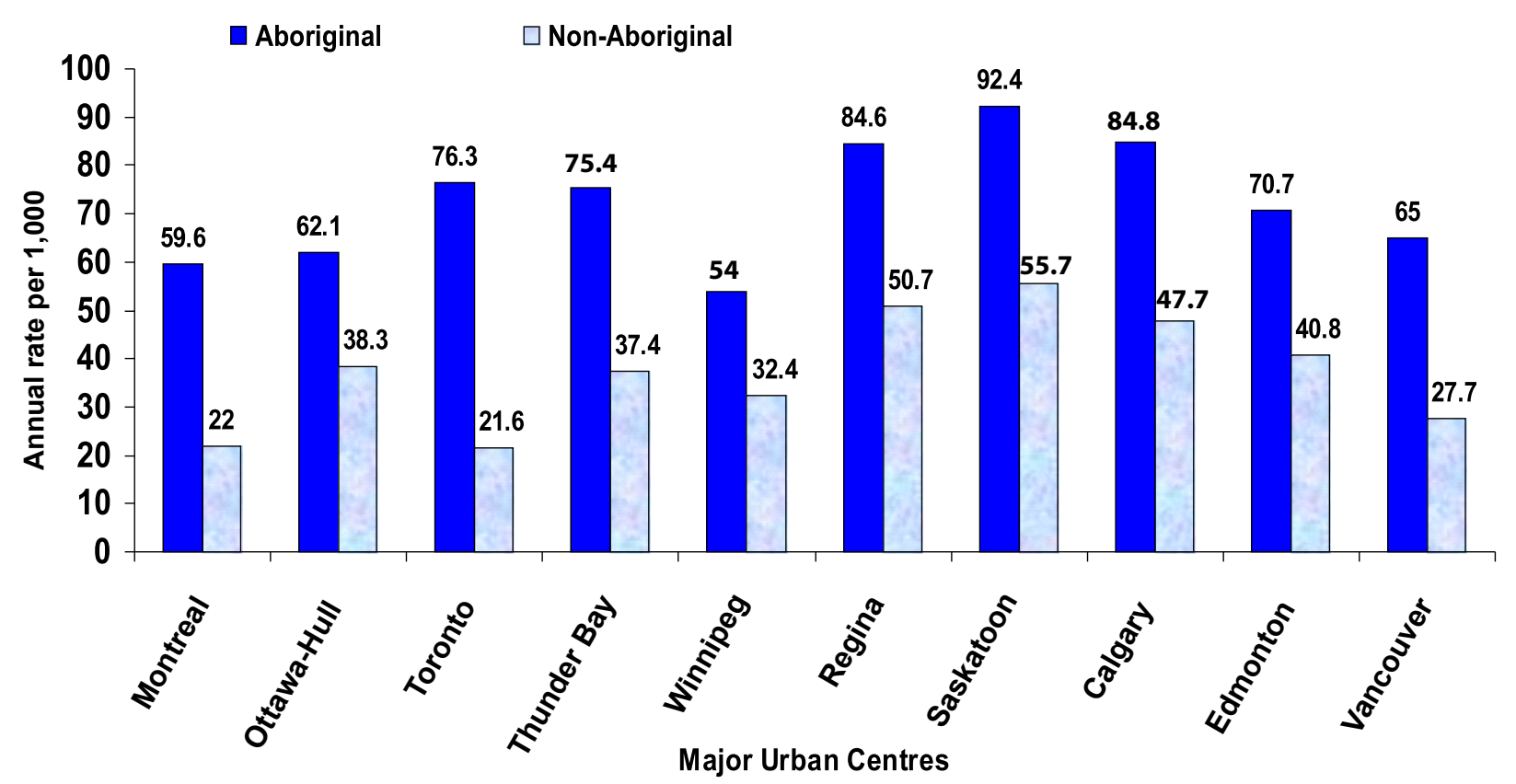

Source: Clatworthy and Norris 2007, Fig. 13.8. Authors' calculations from Statistics Canada, 2001 Census of Canada (unpublished data).

Figure 18: Average Annual Rate of Gross Migration Rate per 1,000 Population for Select Major Urban Centres, Aboriginal and non-Aboriginal Population, Canada, 1996 -2001.

In terms of different Aboriginal groups, Registered Indians consistently have highest rates of in-, out-, and gross-migration, followed by other Aboriginal groups (mainly Métis and Non-Status Indians); nonAboriginals have lowest rates (Figure 19).

The impact of in- and out-migration to CMAs varies across the different CMAs and Aboriginal groups. While some CMAs posted net losses of Aboriginal populations through migration, others - like OttawaHull, Saskatoon, Calgary, and Edmonton-experienced net gains of both Registered Indian and "other Aboriginal" migrants, while Thunder Bay posted net inflows of Registered Indian migrants (Figure 20). 
Registered Indians consistently have the highest rates of in-, out-, and gross-migration, followed by other Aboriginal groups (mainly Métis and Non-Status Indians). Non-Aboriginals have the lowest rates.

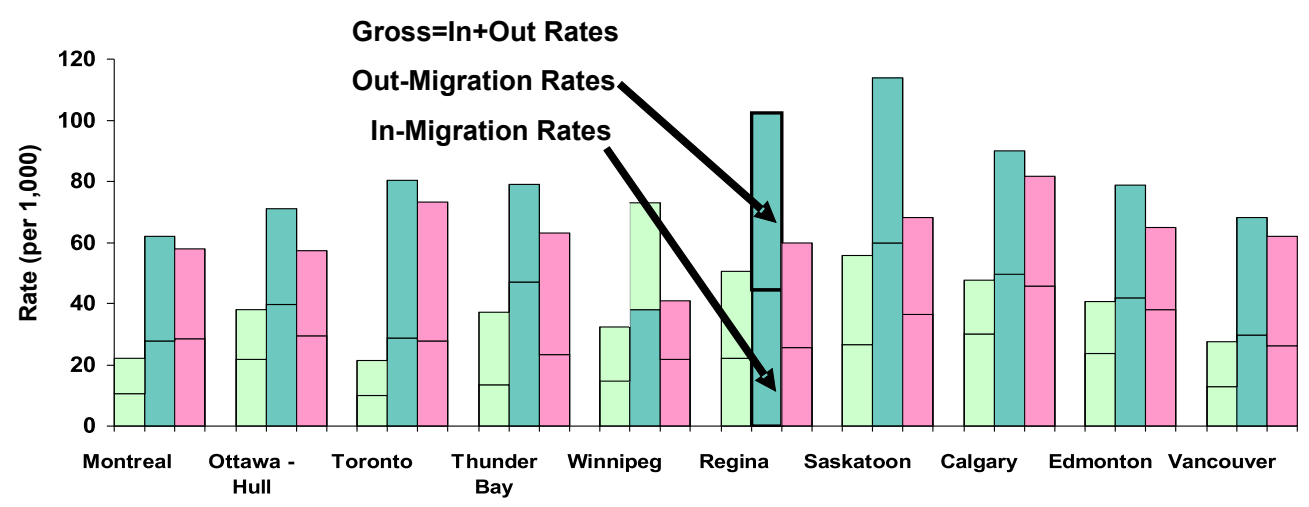

\section{Non-Aboriginal $\square$ Registered $\quad \square$ Other Aboriginal Indian}

Source: Clatworthy and Norris 2007, Figures 13.8 and 13.9. Authors' calculation from Statistics Canada, 2001

Census of Canada (unpublished data).

Figure 19: Average Annual Gross Migration Rates for Select Major Urban Areas, by Registered Indian, Other Aboriginal, and non-Aboriginal Populations, Canada, 1996-2001.

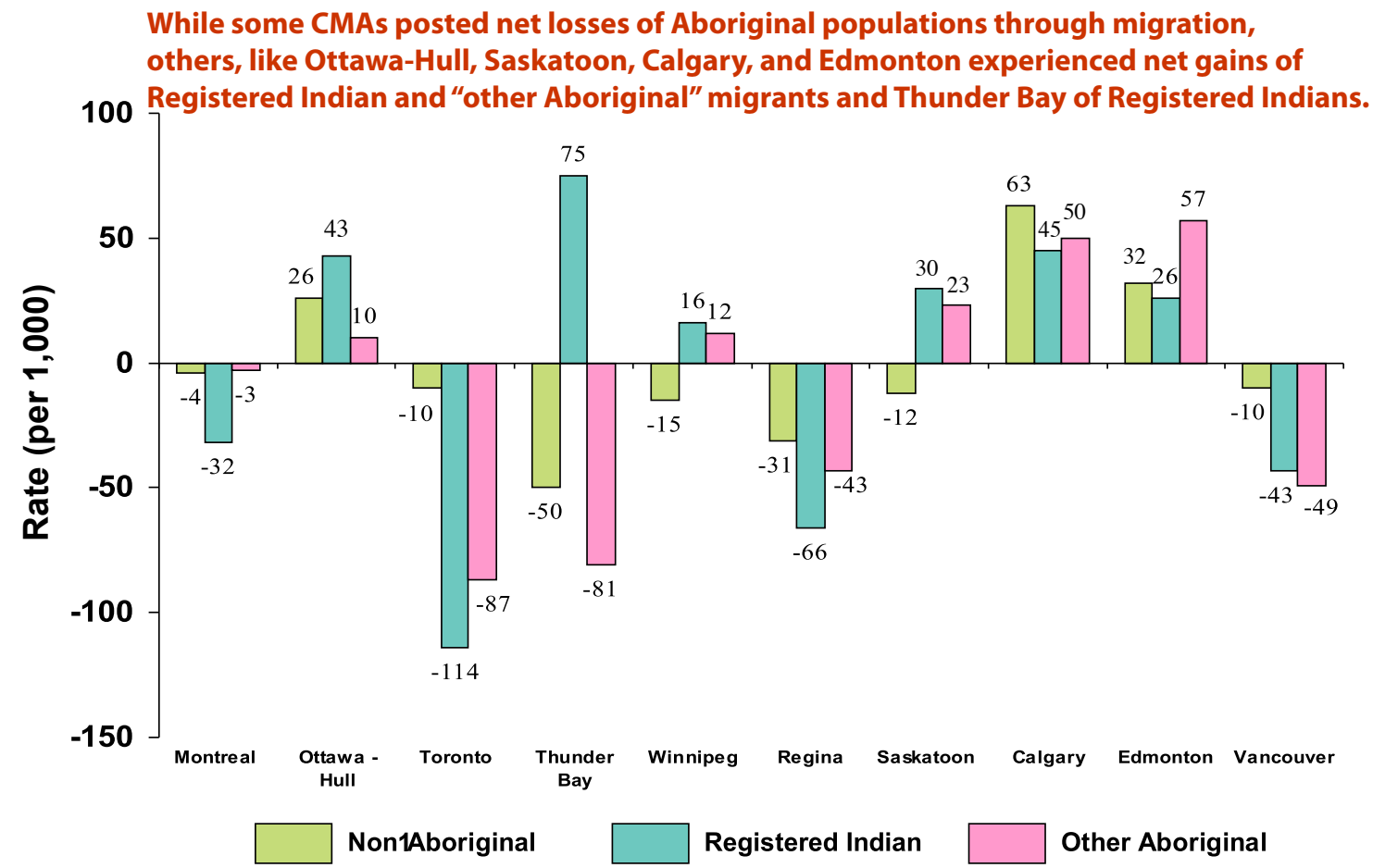

Source: Clatworthy and Norris 2007, Figure 13.10 and 13.11 ; Norris and Clatworthy 2003b. Author's calculations from Statistics Canada, 2001 Census of Canada (unpublished data).

Figure 20: Average Annual Net Migration Rates for Select Major Urban Areas, Registered Indian, Other Aboriginal, non-Aboriginal Populations, 1996-2001. 


\section{Components of Aboriginal Population Growth in Urban Areas, 1996- 2001}

With respect to the components of Aboriginal growth in urban areas, migration is not the only one under consideration. Of course, natural increase is a major demographic factor; however, research has shown that, in the case of Aboriginal population growth, there are other non-demographic factors to consider that can affect urban growth such as legislative changes pertaining to the Indian Act and Registered Indian status (including reinstatements and status inheritance) and ethnic mobility/ drift, concerning changes in self-reporting of Aboriginal identity over censuses (Norris and Clatworthy 2003a). It is ethnic mobility that appears to be the most important factor in explaining the relatively recent dramatic growth of Aboriginal populations in urban areas overall ... not the migration from reserves to cities.

\section{Estimating Ethnic Mobility in Urban Aboriginal Growth}

The contribution of ethnic mobility to the growth of Aboriginal populations can be estimated residually from a decomposition of intercensal growth into the following factors: natural increase, migration, net undercoverage, and a residual component. The residual component of growth that cannot be accounted for by the demographic factors is attributed to ethnic mobility (Clatworthy 2006; Siggner and Costa 2005; and Guimond 2003b). This method is known as "estimation by residual."6

\section{Impact of Ethnic Mobility on Urban Aboriginal Growth}

The article "Aboriginal Populations in Canadian Cities: Why are They Growing so Fast?” by Guimond, Robitaille, and Senécal (2009) provides census-based estimates of the extent of ethnic mobility among Aboriginal populations. Results demonstrate that the extent of ethnic mobility among different Aboriginal groups over the 1996-2001 and 2001-2006 periods has been significant, especially among Métis, and in urban areas.

Estimates produced for the 1986-2001 period show that nearly 42,000 Indians living off-reserve in 2001 did not self-report as Indian in 1986, or one off-reserve Indian in eight (13\%), and over 101,000 Métis in 2001 did not report as Métis in 1986, which 
amounts to four Métis in ten enumerated in 2001 (Guimond 2009). Moreover analysis reveals that over $90 \%$ of ethnic transfers took place in urban areas (Guimond, Robitaille, and Senécal 2009, 15-16).

However, the impacts and significance of ethnic mobility, migration, and natural increase in contributing to urban Aboriginal growth vary by cities, as the next section illustrates.

\section{Aboriginal Population Growth in Major CMAs, 1996-2001}

The major CMAs in this study have clearly experienced different rates of growth in their Aboriginal populations. This next part of the analysis will assess for each city the major contributors to this growth. It should be noted that this assessment requires an estimation of ethnic mobility, which has not yet been undertaken for the 2001 to 2006 intercensal period since the necessary census data retrievals for 2006 were not available at the time of writing. Consequently, this "components of growth" analysis will reference previous research and publications by the authors for the next most recent intercensal period of 1996 to 2001 (Clatworthy and Norris 2007; Clatworthy 2006; Norris and Clatworthy 2003b) to demonstrate the differing impacts of migration and other components in the growth of Aboriginal populations across cities. Analysis is provided for eleven of the twelve cities in this study, since the data on Sudbury were not available for this period.

Range in Rates of Growth across Different CMAs, 1996-2001

Findings from the current study show that, between 1996 and 2001, each of the eleven major urban areas with large Aboriginal populations (representing, combined, almost $27 \%$ of Aboriginal peoples) reported relatively high increases in their Aboriginal populations - all in excess of $10 \%$. However, a wide range of growth was observed over this five-year period, from lows of 11 percent increases for Montreal and 12 percent increases Thunder Bay, to a high of 44 percent for Calgary. Corresponding to these five-year increases, average annual growth rates ranged from 2.2 percent and 2.3 percent to 7.6 percent. In addition, large population increases of 20 percent or more were recorded for the CMAs of Hamilton, Toronto, Saskatoon, Edmonton, and Winnipeg, with corresponding average annual rates of 5.9, 4.7, 4.6, 4.5, 
and 4.0 percent. Smaller five-year increases of between 12 percent and 20 percent were observed for Vancouver, Ottawa-Hull/Gatineau, and Regina, with average annual rates of 3.4,3.0, and 2.9 percent (Figure 21).

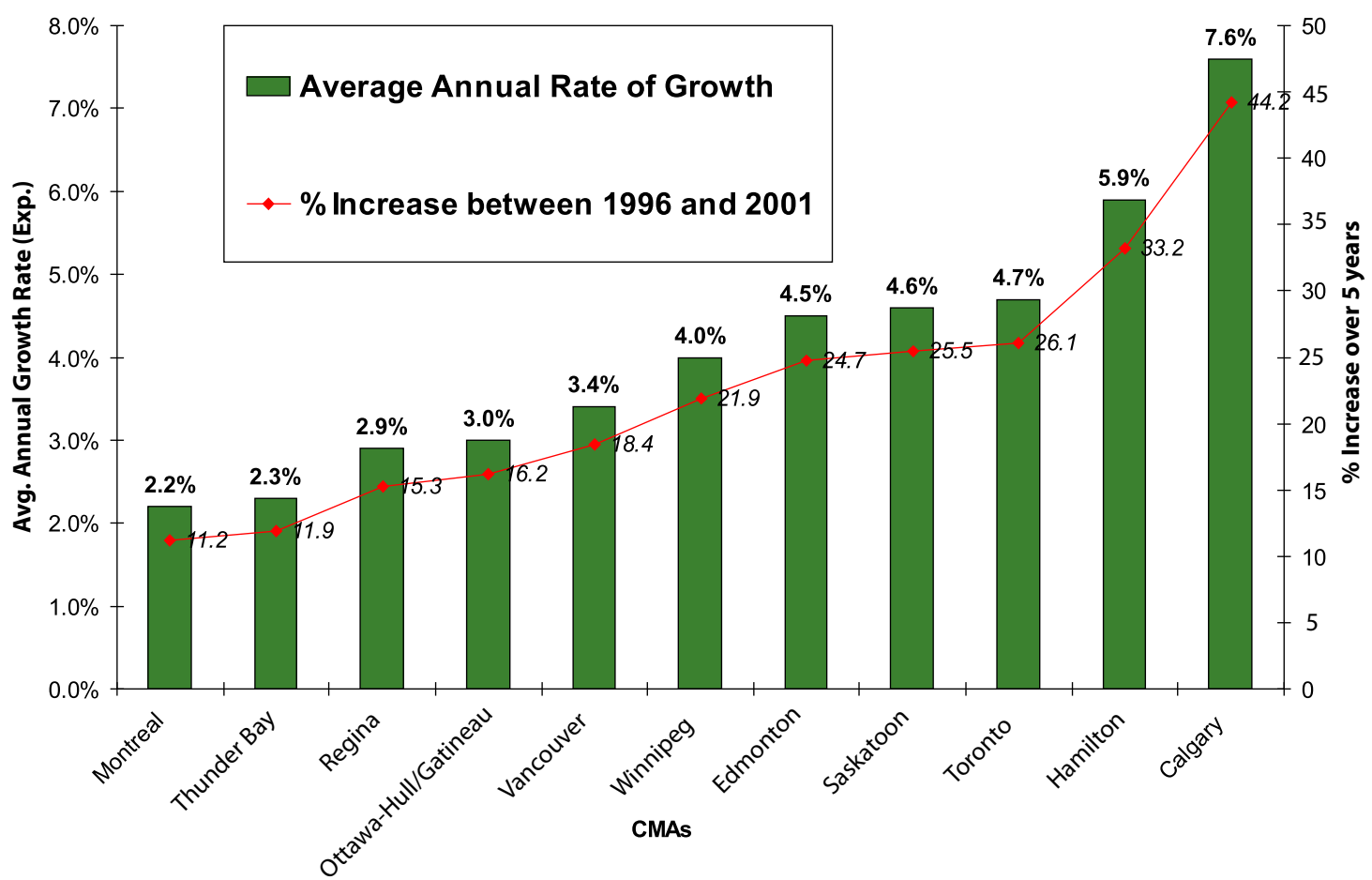

Here the average annual rate is calculated as an exponential average of the five-year growth between 1996 and 2001.

Figure 21: Average* Annual Rate of Aboriginal Population Growth and Percentage Increase for Eleven Major CMAs, 1996-2001 Census (Unadjusted Data).

Average Annual Growth and Net Migration in Major CMAs, 1996-2001

The relative impact of net migration on the growth of the Aboriginal population in CMAs between 1996 and 2001 is assessed by comparing annual net migration rates with annual growth rates. Figure 22 shows the eleven CMAs, ranked by the growth rates of the Aboriginal populations there from lowest to highest, and their corresponding rates of Aboriginal net migration. Seven posted net in-migration, with Calgary, Edmonton, Thunder Bay, and Hamilton having the highest rates, with about eight to ten Aboriginal residents per thousand. While these CMAs had net inflows of migrants, net migration rates generally accounted for only a small component of the total growth rates. The exception was Thunder Bay, where the net in-migration 
rate of 8.1 was more than a third (36\%) of the average annual growth rate (22.5 per thousand) of its Aboriginal population.

Furthermore, the other four cities, even though they saw net outflows of Aboriginal migrants (Montreal, Toronto, Regina, and Vancouver), nevertheless still experienced high rates of population growth. This phenomenon is especially pronounced in Toronto, which saw one of the highest rates of growth in Aboriginal population (46 per thousand) yet, at the same time, had the highest rate of net out-migration of the eleven CMAs, at nearly 20 per thousand Aboriginal residents.

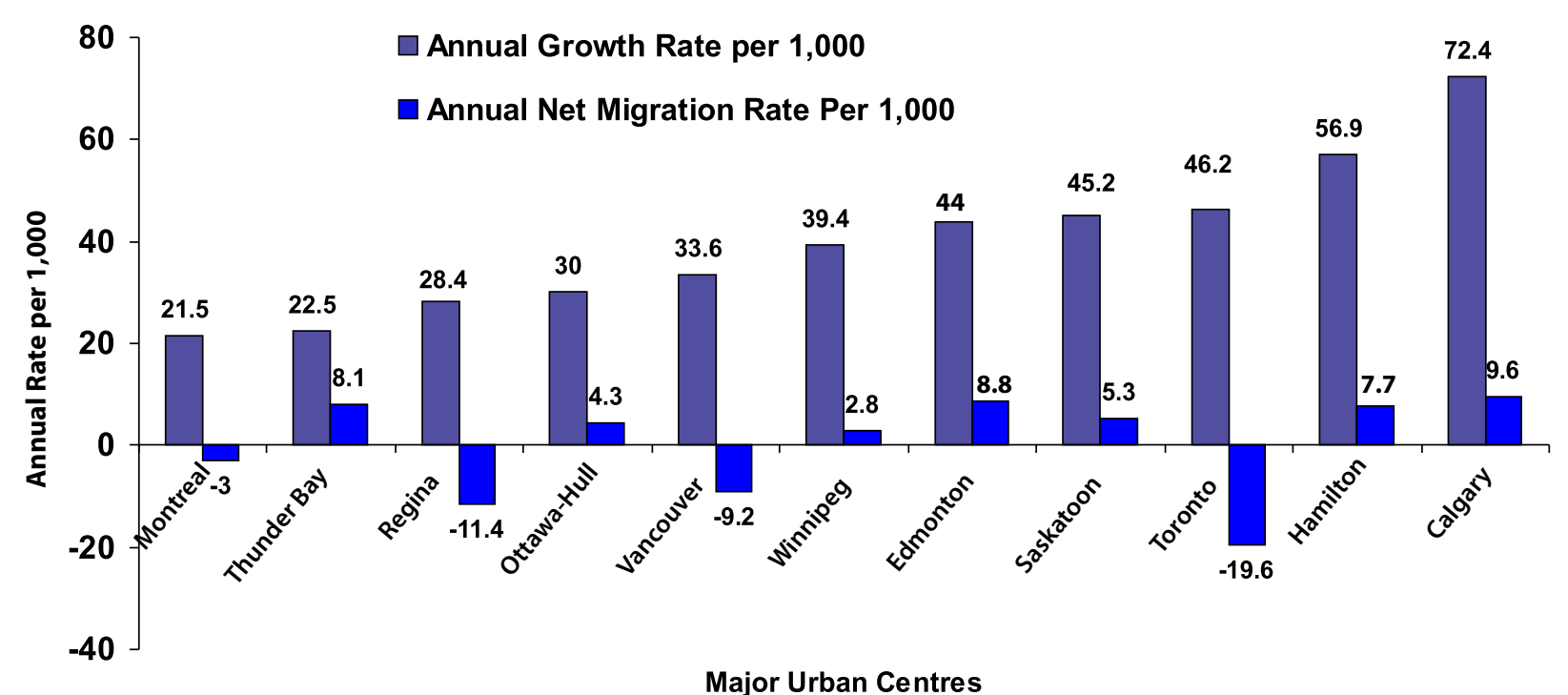

Source: Clatworthy and Norris 2007, Figure 13.11. Authors' calculations from Statistics Canada, 2001 Census of Canada (unpublished data; CMA of Hamilton added separately).

*Note: Average Annual Growth Rate is an arithmetic average.

Figure 22: Average Annual Growth* and Net Migration Rates per 1,000 Aboriginal Population by Select Major Urban Centres, Canada, 1996-2001.

These findings would suggest that, for most major urban areas, growth in Aboriginal populations must have resulted not from migration but from other factors, such as natural increase and ethnic mobility. 


\section{Components of Aboriginal Population Growth for Selected Major CMAs, 1996-2001}

The following CMA-level component analysis provides results for eleven of the twelve cities in this study (excluding Sudbury), which were analysed with respect to their long-term population trends. It should be noted that, with respect to geography, the CMAs used in this analysis do include rural fringes and any reserves located within their boundaries; as well, they do not comprise the total Aboriginal CMA population. As such, overall results from this selected CMA-level analysis are not directly comparable to the 1996-2001 component analyses at the national level in Table 2 of this paper.

Figure 23 shows the decomposition of the growth of the Aboriginal population in absolute numbers over the 1996-2001 period for the eleven CMAs, which are ranked again by population growth rates from low to high. The first bar represents estimated population change due to natural increase, the second bar net migration, the third ethnic mobility, and the fourth bar total population growth. It should be noted that, in the cases of natural increase and ethnic mobility, these components are estimated and that estimates take into account growth due to differential net under coverage (not shown). Beginning with the component of migration, it appears that migration is generally not a major factor in Aboriginal population growth. Although seven of the cites posted net inflows of Aboriginal migrants over the five-year period, the impact of net migration accounted for a relatively small share of their overall growth, with perhaps the exception of Thunder Bay (at about 25\%) and Hamilton (12\%). While the other four cities of Vancouver, Toronto, Regina, and Montreal saw net losses of population through migration, all these cities, especially Toronto, nevertheless recorded high rates of population growth.

Ethnic mobility appears to be the largest component of growth for most cities, and in some cities, such as Vancouver, Toronto, Ottawa-Hull, and Montreal, tends to account for a large majority of the growth observed during the period.

However, it is also important to note that natural increase, compared to population changes from other components, remains a significant contributor to Aboriginal population growth in most of the CMAs, and especially so in Winnipeg, Saskatoon, Regina, and Thunder Bay. In other cities like Vancouver and Calgary, natural increase accounted for a smaller share of total population growth. 


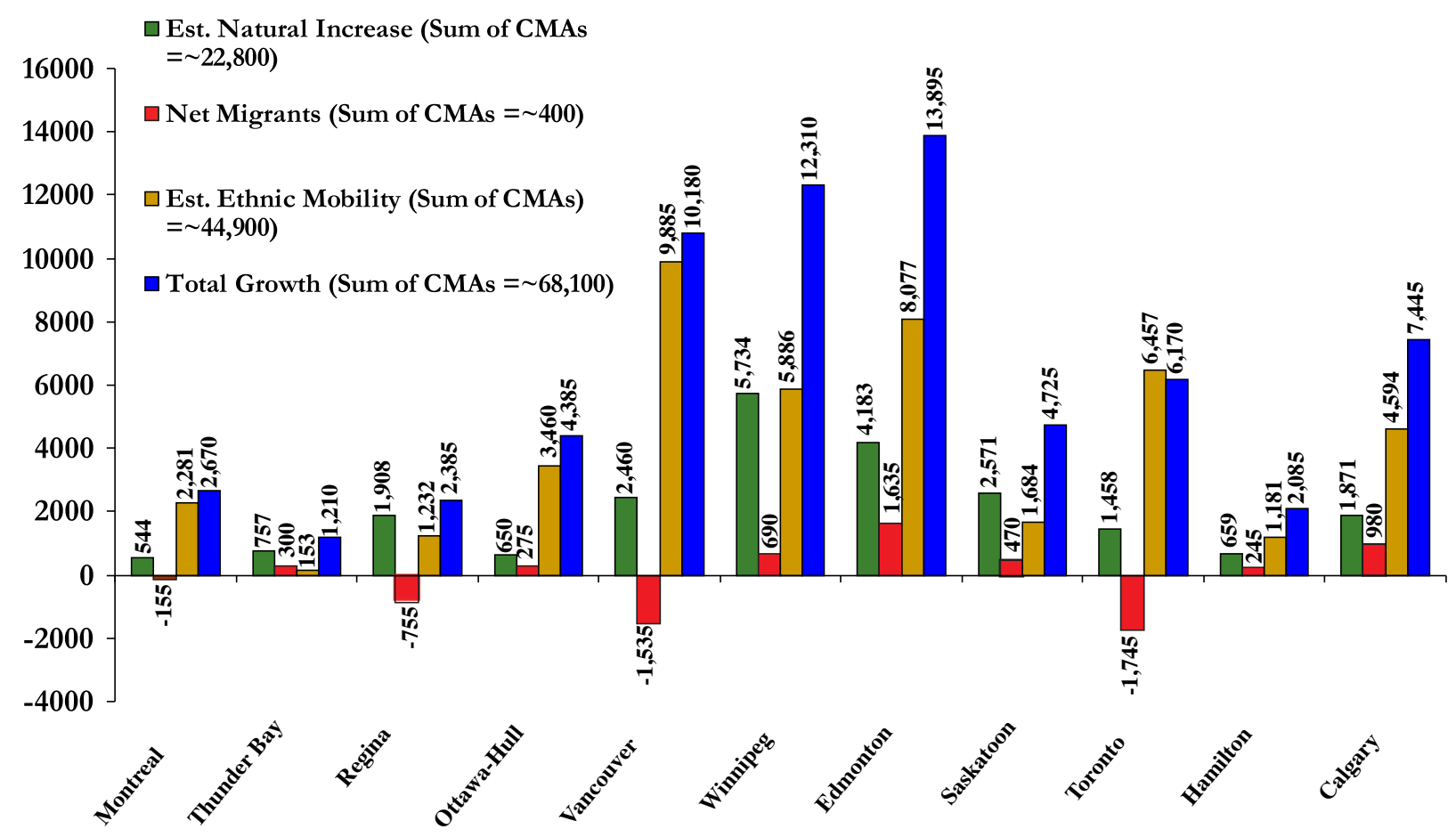

Source: Authors' calculations from Statistics Canada, 1996 and 2001 Censuses of Canada (unpublished data).

Figure 23: Components of Aboriginal Population Growth, for Selected Major CMAs, 1996-2001.

Indirect Contribution of Migration to Aboriginal Urbanization through Natural Increase

With respect to the impact of migration on urbanization, while even though the direct effects of net migration (i.e., net gains or losses of population) may be small, indirect impacts are possible. The age-gender composition of the urban population may be affected by the inflow of young adult Aboriginal migrants of child-bearing ages, which could have the indirect effect of contributing to urban growth through natural increase (i.e., births minus deaths).

Figure 24 also shows the decomposition of the growth of the Aboriginal population for the same components but in terms of their percentage share of the growth in the CMA's Aboriginal population over the 1996 to 2001 period. 


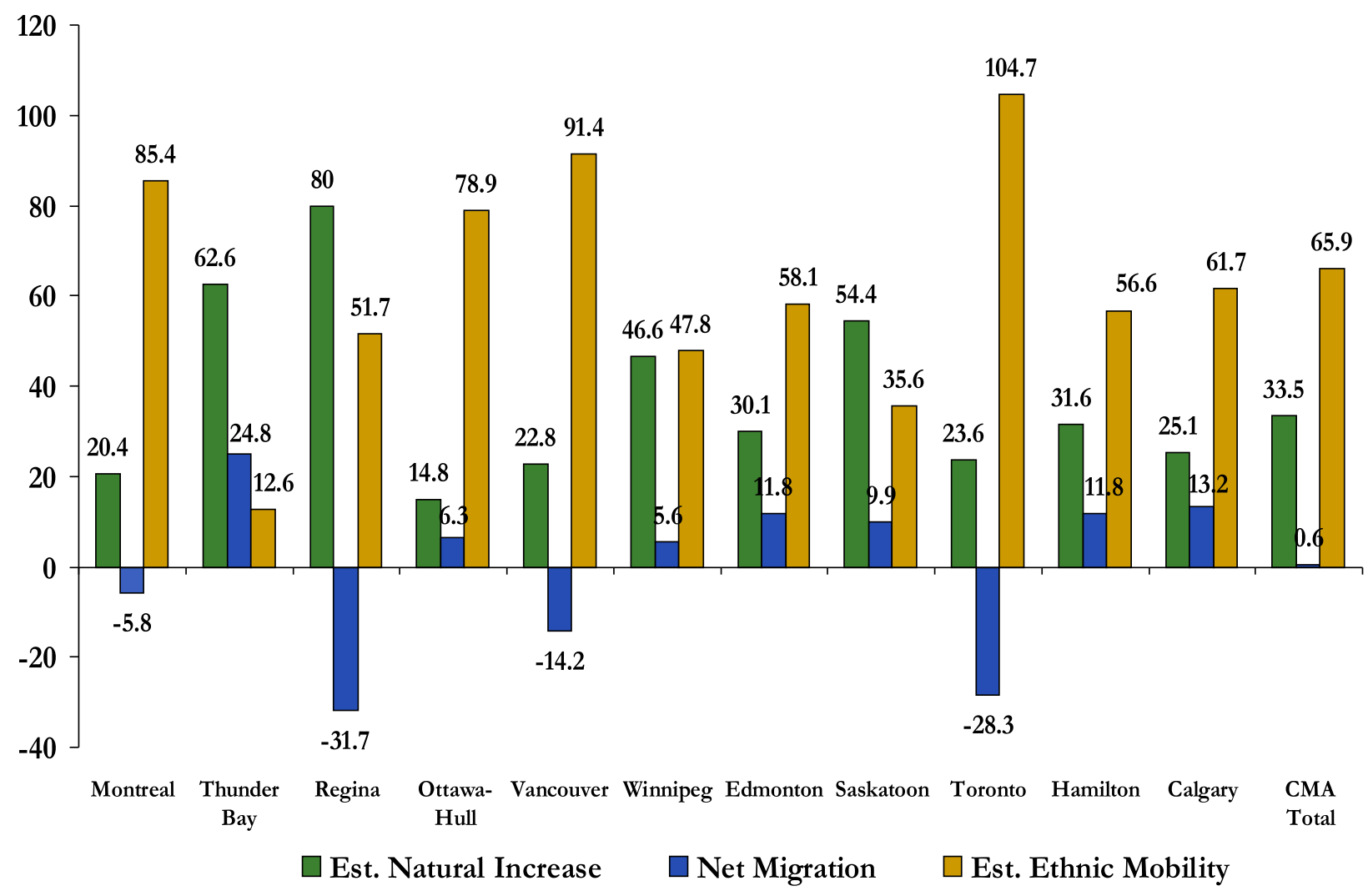

Source: Authors' calculations from Statistics Canada, 1996 and 2001 Censuses of Canada (unpublished data).

Figure 24: Ethnic Mobility, Natural Increase, and Migration Share (\%) of Aboriginal Population Growth*, Selected Major CMAs, 1996-2001.

This analysis demonstrates the significance of ethnic mobility in general as a factor of the growth of Aboriginal populations in the largely urban CMAs. We estimate ethnic mobility to account for the majority (about two-thirds, or $65.9 \%$ ) of the growth of Aboriginal populations in these eleven CMAs overall between 1996 and 2001. Nearly all of the remaining growth is accounted for by natural increase (33.5\%). About 0.6 percent of growth is attributable to migration.

However, while ethnic mobility is significant in explaining the dramatic growth in urban areas in general, its impact does vary widely from city to city, and reflects the fact that natural increase is also an important factor for some cities. Natural increase appears to be a relatively major contributor to Aboriginal population growth in the selected prairie cities (47\% in Winnipeg, 55\% in Saskatoon, and $80 \%$ in Regina), as well as 
Thunder Bay (63\%). Both natural increase and net migration are relatively significant contributors to population increases in Edmonton, Calgary, Ottawa-Hull, Thunder Bay, and Hamilton. In the major urban areas of Vancouver, Toronto, and Montreal, which saw net losses of population through migration (i.e., net outflow of migrants), ethnic mobility accounts for at least 80 percent of the growth of their Aboriginal populations.

In other words, these findings suggest that not only has urban Aboriginal population growth occurred at varying rates among the highlighted urban areas, but that growth among these urban areas has also resulted from different processes.

\section{Aboriginal Populations in Urban Areas: A Preliminary Typology of Growth Patterns, Components, Size, and Composition}

The findings of this census-based analysis suggest that urban areas differ significantly in the population characteristics of their Aboriginal residents, not only in terms of their population size but also with respect to longterm and recent patterns of population growth and components of growth. Furthermore, the differences themselves have implications for age-gender structure, period of urbanization (in relation to migration flows to urban areas and generations of urban residents), and the Aboriginal groups comprising various urban Aboriginal populations. Thus, various dimensions of urban Aboriginal populations could be considered in distinguishing different types of urban areas, according to population characteristics.

The results of this eleven-city analysis suggest the beginnings of a typology that distinguishes urban Aboriginal populations on the basis of their historical growth patterns, current components of growth, population size, and potentially other relevant factors. A first attempt at developing such a typology is presented in Table 3 which groups the eleven CMAs highlighted in this study according to three major criteria, including: longterm (1951 to 2006) patterns of population growth; current (1996-2001) components of population growth; and size of the Aboriginal population, the latter which could be seen more as a sub-category of the three main groupings of cities.

The following provides a brief discussion concerning the classification of the eleven CMAs by each of the typology's three criteria. 


\section{Long-term (1951 to 2006) Patterns and Current (1996 -2001) Components of Population Growth, and Population Size}

Based on the analysis of population changes for these eleven CMAs over the 1951 to 2006 period, three types of growth patterns in Aboriginal populations can be identified. Patterns of long-term growth in combination with the current components of growth analysis for the 1996-2001 period, are used to assign each of the eleven urban areas into groups based on population growth profiles. Urban areas falling within each group were further classified by the size of their Aboriginal populations. These categories, and their corresponding CMAs as outlined in Table 3, are as follows.

1. Urban areas with rapid growth in Aboriginal population at the beginning of the period of urbanization, with differentials in growth between previous and more recent periods of urbanization, and posting significant increases in absolute numbers over the 1981-1996 period. For these areas, natural increase is a major component of current growth, accounting for at least practically half of Aboriginal population growth.

CMAs which share these growth characteristics are the prairie cities of Winnipeg, Saskatoon, and Regina. They vary in the size of their Aboriginal populations, with Regina falling into the category of between 8,000 and less than 20,000; Saskatoon with between 20,000 and 30,000; and Winnipeg with an Aboriginal population exceeding 68,000.

2. Urban areas with their generally highest growth occurring at the outset of the period of urbanization (i.e., the 1950s and 1960s), with some differentials in growth over time, with less pronounced increases during the1981-1996 period of increases, and experiencing high growth more recently. For these areas, both natural increase and net migration are major contributors to their Aboriginal populations.

CMAs which share these growth characteristics are Edmonton, Calgary, Ottawa-Hull/Gatineau, Thunder Bay, and Hamilton. Again, these CMAs vary in the size of their Aboriginal populations, with Thunder Bay and Hamilton in the category of between 8,000 and less than 20,000 Aboriginal residents; Calgary, Ottawa-Hull/Gatineau in the range of 20,000 to 30,000; and Edmonton with an Aboriginal population of at least 40,000. 
3. Urban areas with ongoing growth, some experiencing recently high growth in Aboriginal populations, in spite of net out-migration. In these cities ethnic mobility accounts for at least 80 percent of growth.

CMAs that share these growth characteristics are the cities of Vancouver, Toronto, and Montreal. These cities also vary in the size of their Aboriginal populations, with Montreal in the category of between 8,000 and less than 20,000 Aboriginal residents, Toronto with between 20,000 and 30,000 , and Vancouver with a population of at least 40,000 .

\begin{tabular}{|c|c|c|c|}
\hline $\begin{array}{c}\text { Long-term growth } \\
\text { Patterns, over } 1951 \\
2006 \text { period }\end{array}$ & $\begin{array}{l}\text { Current (1996-2001) } \\
\text { Components of } \\
\text { Population Growth }\end{array}$ & $\begin{array}{c}\text { Aboriginal } \\
\text { Population, } 2006\end{array}$ & $\begin{array}{c}\text { CMAs with pattern \& } \\
\text { component } \\
\text { characteristics }\end{array}$ \\
\hline \multirow{3}{*}{$\begin{array}{l}\text { Rapid growth at } \\
\text { beginning; differentials } \\
\text { between past \& recent } \\
\text { growth; significant } \\
\text { increases in absolute } \\
\text { numbers over } 1981\end{array}$} & \multirow{3}{*}{$\begin{array}{l}\text { Natural increase is a } \\
\text { major component, } \\
\text { accounts for at least } \\
\text { practically half of growth } \\
\text { in prairie cities }\end{array}$} & At Least 40,000 & Winnipeg \\
\hline & & $\begin{array}{l}\text { Between } 20,000 \\
\text { and } 30,000\end{array}$ & Saskatoon \\
\hline & & $\begin{array}{c}\text { Between } 8,000 \text { and } \\
\text { less than } 20,000\end{array}$ & Regina \\
\hline \multirow{2}{*}{$\begin{array}{c}\text { Generally highest } \\
\text { growth at beginning; } \\
\text { some cities differentials } \\
\text { over time, and } 81-96 \\
\text { increases less } \\
\text { pronounced; recent } \\
\text { high growth }\end{array}$} & \multirow[b]{2}{*}{$\begin{array}{l}\text { Both natural increase and } \\
\text { net migration contributors } \\
\text { to growth }\end{array}$} & At Least 40,000 & Edmonton \\
\hline & & $\begin{array}{l}\text { Between } 20,000 \\
\text { and } 30,000 \\
\text { Between } 8,000 \text { and } \\
\text { less than } 20,000\end{array}$ & $\begin{array}{c}\text { Calgary, } \\
\text { Ottawa-'Hull/Gatineau } \\
\text { Thunder Bay, Hamilton }\end{array}$ \\
\hline \multirow[b]{3}{*}{$\begin{array}{l}\text { Ongoing and continued } \\
\text { growth - some cities } \\
\text { with recent high growth }\end{array}$} & \multirow{3}{*}{$\begin{array}{l}\text { Ethnic mobility accounts } \\
\text { for at least } 80 \% \text { of } \\
\text { growth; negative net } \\
\text { migration (net outflow of } \\
\text { migrants) }\end{array}$} & At Least 40,000 & Vancouver \\
\hline & & $\begin{array}{c}\text { Between } 20,000 \\
\text { and } 30,000\end{array}$ & Toronto \\
\hline & & $\begin{array}{c}\text { Between } 8,000 \text { and } \\
\text { less than } 20,000\end{array}$ & Montreal \\
\hline
\end{tabular}

Table 3: Typology of Long-term (1951-2006) Patterns and Current (1996-2001) Components of Aboriginal Population Growth, Selected Urban Centres (CMAs). 


\section{Other Criteria for Future Consideration in Typology}

It should be emphasized that these current criteria represent some preliminary dimensions in shaping a proposed typology. There are certainly a number of potentially relevant criteria that warrant future consideration but have not as yet been analyzed at the time of writing. Some examples of such items include: the percentage of the city population that is Aboriginal; the Aboriginal composition-First Nation, Métis and Inuit-of the city's Aboriginal population; the various city patterns of net in- or out-migration (Aboriginal and non-Aboriginal); the reasons for migration to and from cities; and estimated duration of residency and number of Aboriginal generations born and raised in the urban area.

\section{Initial Implications of Typology for Aboriginal Populations in Different Urban Areas}

This section explores some initial implications of the different types of long-term patterns and components of Aboriginal population growth, as outlined in the preliminary typology, which could be relevant in addressing the characteristics, needs, and services of Aboriginal populations across different urban areas, including those of the Urban Aboriginal Strategy (UAS) cities.

\section{Implications of Long-term growth patterns and size of Aboriginal Populations in Urban Areas}

A city's long-term growth patterns and size of its Aboriginal populations can have significant implications with respect to the social networks and support structures that exist among Aboriginal communities, families, and individuals within that city. For example, cities with long-established and large Aboriginal populations reflecting significant past growth, like Winnipeg, may be more likely to have:

- third and fourth generations of urban residents, as successive generations / descendents of migrants are born and raised in urban areas;

- more urban Aboriginal community / neighbourhood organizations and services with increasing emphasis on organizational capacity and community infrastructure; 
- reduced migration to and from reserves as Aboriginal communities and social networks and support structures develop in urban areas; and,

- programming requirements for older, as well as younger, generations.

On the other hand, urban areas experiencing more recent growth and gains of Aboriginal populations through migration may be more likely to have:

- newcomers, from non-urban Aboriginal communities; mainly Indian reserves; Inuit settlements;

- requirements for developing, putting in place infrastructure, service delivery, housing; and,

- perhaps ongoing migration to and from communities of origin, as well as between cities - small and large.

In the case of smaller (non-CMA) cities, continued long-term net outmigration over 1951-2006 may reflect less availability in general for new infrastructure, service delivery, and organizational capacity.

\section{Implications of Components of Growth for Aboriginal Populations in Urban Areas}

Even with minimal net migration, high rates of in- and out-migration to and from cities "churn" and, along with high residential mobility, can impact service delivery and areas such as education (attendance, turnover, achievement). Apart from the net gain or loss of migrants, the impact of migration on age-gender composition of urban Aboriginal population can also affect population growth indirectly, through natural increase with the influx of youth, young adult migrants to cities, and consequently, the needs and services of young families (e.g., housing).

As the findings of this analysis demonstrated, while ethnic mobility can have a significant impact on the growth of Aboriginal populations in urban areas, its impact does vary across cities, and may reflect a number of factors, such as:

- regional variations in identity (such as Métis) associated with cultural, historical, and political dimensions;

- effects of older generations of earlier migrants 
residing in cities who may have indicated their Aboriginal identity at a later time period; and,

- effects of growing population with Aboriginal origins, a potential source of Identity populations.

Variations in the First Nation, Inuit, and Métis composition of Aboriginal populations across cities may also reflect differences in trends, levels, and periods of urbanization, associated with migration and other components of growth, such as natural increase, ethnic mobility, and legislation (e.g., 1985 Indian Act revisions and reinstatements). For example, prior to 1985, more women characterized the out-flow of Registered Indian migrants from reserves to cities, leading to gender imbalance and bias both on reserve and in urban areas, whereas recent migration patterns are more gender balanced (Clatworthy and Norris, unpublished paper).

In addition to the impacts of different components of growth on the demographic and group composition of Aboriginal populations in urban areas, migration has effects on the socio-economic characteristics of the population. In this respect, the impact of high rates of growth due to ethnic mobility, especially among the Métis, can be significant, affecting not only the size of the Aboriginal population but also its composition. Such consequences, particularly in relation to the impact of ethnic mobility, can have implications for the interpretation of both demographic, socioeconomic, and urbanization trends:

High rates of change in ethnic affiliation can affect not only the size of a population but also its composition, particularly if the socio-demographic characteristics (e.g., educational attainment, employment earnings, family size) of the pool of ethnic drifters are markedly different from those of the base population). . . . As such trends with respect to socio-demographic characteristics of urban Aboriginal people, and particularly Métis, need to be interpreted with caution and with awareness of the potential impact of ethnic mobility on these trends ... The misinterpretation of trends towards urbanization could result in: (a) over-emphasis on migration from Indian reserve to cities; (b) a policy shift away from First Nations and Inuit communities (Guimond, Robitaille, and Senécal 2009, 16). 


\section{Conclusion}

\section{Role of Migration in Aboriginal Urbanization:}

To what extent has migration contributed to the rapid increase in the Aboriginal populations living off-reserve in large urban areas?

During the initial period of urbanization, particularly between 1951 and 1971, migration appeared to be an overall contributing factor to the growth of the Aboriginal population in urban areas. However, since this earlier period of urbanization, in spite of high levels of movement, the contribution of migration as a component of Aboriginal growth has diminished considerably in urban areas overall, with ethnic mobility and to some extent natural increase accounting for much of urban growth in general. However, at the individual city level, migration is a factor in the growth of Aboriginal populations for some specific cities. For many urban areas though, high rates of Aboriginal population are due to ethnic mobility and natural increase.

As well, there are some underlying factors to consider in the interplay of migration and urbanization. For example, the recent lessening of high mobility of Aboriginal populations may suggest eventual convergence towards non-Aboriginal rates, owing to greater residential stability of Aboriginal populations in urban areas over time. And, while net migration effects are small, the age-gender compositional effects of migration, of Aboriginal youth and young adults migrating to cities could indirectly contribute to population growth through natural increase. In some CMAs, like Winnipeg, natural increase is as major a contributor as ethnic mobility to Aboriginal population growth; this is in contrast to Toronto, where natural increase is much less significant than ethnic mobility.

Thus, while migration originally contributed directly to the growth

of Aboriginal populations in urban areas at the beginning of urbanization, it would appear that it has not been a direct contributor since, although it may indirectly impact through natural increase. For now, though, ethnic mobility generally appears to be the most important factor in explaining dramatic growth of Aboriginal populations in urban areas overall.

\section{Typology of Aboriginal Population Growth, Size, and Composition}

The findings of this study reveal that cities / urban areas across Canada 
clearly do differ not only in the size of their Aboriginal populations, but also in their long-term patterns of Aboriginal population growth and their current components of growth. As a consequence of these differences, Aboriginal populations in these different cities can also differ in their agegender structure, the number of generations residing in urban areas, and their First Nation, Inuit, and Métis composition.

All of these demographic differences play a role in shaping the range and variation across cities in the characteristics, needs, and services of their urban Aboriginal populations. For example, as noted, in urban areas where Aboriginal populations are long-established, generations of urban residents are more likely to have developed their own urban institutional structures and completeness. These could impact on changing ties and reduced migration back to home "reserve" communities.

In conclusion, patterns and trends of Aboriginal urbanization and migration of over the past fifty years still hold considerable relevance for the characteristics and state of Aboriginal populations in urban areas today. Cities across Canada have experienced both different and similar histories and patterns of Aboriginal population growth and migration. Addressing such patterns as outlined in the preliminary urban Aboriginal typology would serve to better interpret and understand the various components shaping not only the growth but also the socio-demographic and group composition of their Aboriginal populations today, and their implications for needs and services.

Furthermore, this typology could be extended to incorporate the population-related dimensions of age-gender structure, generations and Aboriginal group composition, and socio-economic characteristics. As such, the development and application of a typology of Aboriginal populations in different urban areas would be an area for future research, particular with respect to interpreting and understanding the implications for the growth, composition and needs, and services of Aboriginal populations in different cities across Canada, including those of the Urban Aboriginal Strategy.

\section{(Endnotes)}

1. This paper was prepared with the support of the Office of the Federal Interlocutor (OFI), Indian and Northern Affairs Canada (INAC). The authors acknowledge with thanks the comments and feedback provided by 
Jodi Bruhn of OFI.

2. This paper builds on preliminary research findings that were presented by the authors at the "Session on Indigenous Urbanization Internationally: Geographic Variations" as part of the workshop "Indigenous Urbanization in International Perspective," held at the University of Saskatchewan in October of 2009.

3. In his discussion of the urbanization of American Indians in the United States, Snipp argues from a long-term view of history that American Indians lived in urban areas before the time of Columbus, and that "de-urbanization" preceded the contemporary urbanization observed in the twentieth century. Within the context of recent history, Snipp observes that urbanization of American Indians did not begin until after the end of World War II (Snipp, 2009). This is similar to the beginnings of contemporary urbanization of Aboriginal populations in Canada, which appeared after the first half of the twentieth century.

4. Two different types of average annual growth rates are used in this study: exponential averages, and arithmetic averages. Exponential averages are used throughout for most of the analyses, including all of the trend analysis of long-term and intercensal growth of Aboriginal populations. Arithmetic averages have been used in the components of growth analysis. The calculations of each type of average annual growth rate follow:

Exponential growth rates represent the effects of compounding over time. The average annual exponential growth rate is calculated by first dividing the initial population at the beginning of the period by the population at the end of the period. This value in the formula is then raised to the power that is equal to 1 divided by the number of time intervals for which the average growth rate is calculated. In the case of a five-year period, the value of the power would be $1 / 5=.2$. The formula can be illustrated using populations from the 2001 and 2006 Censuses. The average annual growth rate would be calculated as follows, using 5 as the number of years over the period:

Exponential Average $\left.=\left(\left(\mathrm{P}_{2006} / \mathrm{P}_{2001}\right)^{0.2)}\right)-1\right)$

Here arithmetic averages, representing an annual percentage rate of change, are obtained by dividing the percent change in population between two time periods, based on the midpoint of the two populations by the number of years between the two populations. For example, again using populations from the 2001 and 2006 Censuses, the average annual growth rate would be calculated as follows, using 5 as the number of years over the period: 
Arithmetic Average $\left.=\left(\left(\mathrm{P}_{2006-} \mathrm{P}_{2001}\right) /\left(\left(\mathrm{P}_{2001}+\mathrm{P}_{2006}\right) / 2\right) / 5\right) * 100\right)$

5. This analysis incorporates existing findings from the literature on the Aboriginal population overall, although the migration flows with respect to reserves in Tables 1 and 2 are largely specific to Registered Indians. Separate such analyses of each Aboriginal groups (Registered Indian, Métis, Non-Status Indian, and Inuit) would be possible, but beyond the scope of this present paper. Previous research suggests that migration flows appear to have minimal impact on the growth of Métis and Non-Status Indian populations in urban areas (Clatworthy and Norris 2007; forthcoming; Norris and Clatworthy 2003).

6. This method of "estimation by residual" can be more precisely explained as follows:

Calculating the population expected in year $t+n(P x t+n)$ by taking the population observed in $\mathrm{t}(\mathrm{Pt})$ and subtracting an estimated of deaths (D), adding net migration $(\mathrm{M})$ and all other know factors (net undercoverage of the population) (V) for the observation period $(\mathrm{t}, \mathrm{t}+\mathrm{n})$, assuming that ethnic mobility in nil:

$(\mathrm{Pxt}+\mathrm{n})=\mathrm{Pt}-\mathrm{D}(\mathrm{t}, \mathrm{t}+\mathrm{n})+\mathrm{M}(\mathrm{t}, \mathrm{t}+\mathrm{n})+\mathrm{V}(\mathrm{t}, \mathrm{t}+\mathrm{n})$

Subtracting the population expected in year $\mathrm{t}+\mathrm{n}(\mathrm{Pxt}+\mathrm{n})$ from the population observed in that year $(\mathrm{POt}+\mathrm{n})$. The result of this subtraction represents the estimate of net ethnic mobility $(\beta)$ during the observation period $(\mathrm{t}, \mathrm{t}+\mathrm{n})$ :

$\beta(t, t+n)=(P O t+n)-(P x t+n)$

(Guimond 2003b, 105)

\section{References}

Clatworthy, Stewart. 1981. "Patterns of Native Employment in the Winnipeg Labour Market.” Technical Study prepared for the Task Force on Labour Market Development. Ottawa.

Clatworthy, S.J. 1994. “The Migration and Mobility Patterns of Canada's Aboriginal Populations." Ottawa: Indian and Northern Affairs Canada.

Clatworthy, S.J. 2006. A Profile of Aboriginal Children, Youth and Young Adults Living Off-reserve. Report prepared for Aboriginal Affairs Branch, Canadian Heritage, Ottawa. 
Clatworthy, S.J. and M.J. Norris. 2007. “Aboriginal Mobility and Migration in Canada: Trends, Recent Patterns and Implications, 1971 to 2001." In Aboriginal Policy Research: Moving Forward, Making a Difference. Vol. IV, ed. J.P. White, S. Wingert, D. Beavon, and P. Maxim. Toronto: Thompson Educational Publishing.

Clatworthy, S.J. and M.J. Norris. Unpublished paper. “Aboriginal Mobility and Migration in Canada: Trends, Recent Patterns and Implications, 1971 to 2006."

Guimond, E. 1999. "Ethnic Mobility and the Demographic Growth of Canada's Aboriginal Population from 1986-1996." In Report on the Demographic Situation in Canada, 1998-1999, ed. A. Belanger, 187-200. Statistics Canada, Ottawa: Industry Canada, Catalogue \#91-209-XPE.

Guimond, E. 2003a. "Fuzzy Definitions and Population Explosion: Changing Identities of Aboriginal Groups in Canada." In Not Strangers in These Parts: Urban Aboriginal Peoples, ed. David Newhouse and Evelyn Peters, 35-49. Ottawa: Policy Research Initiative, Ottawa.

- - - 2003b. "Changing Ethnicity: The Concept of Ethnic Drifters." In Aboriginal Conditions: Research as a Foundation for Public Policy, ed. J. White, P. Maxim, and D. Beavon, 91-107. Vancouver: UBC Press.

Guimond, E., N. Robitaille, and S. Senécal. 2009. "Aboriginal People in Canadian Cities: Why are They Growing so Fast?" In Canadian Issues, Winter 2009: 11-17. Indian and Northern Affairs Canada, 2011. "Urban Aboriginal Strategy - Background.” http://www.aincinac.gc.ca/ai/ofi/uas/bkg-eng.asp.

Jette, D. and M. Snider. 2009. "Affiliation of First Nation Communities with Urban Zones: Analysis of Census data 1996-2006." Based on a presentation to the Aboriginal Policy Research Conference, Strategic Research, and Analysis Directorate, Indian and Northern 


\section{Affairs Canada.}

Nagler, Mark. 1973. "Indians in the City: A Study of the Urbanization of Indians in Toronto." 2nd ed. University of Ottawa, Ottawa: Canadian Research Centre for Anthropology, Saint Paul University.

Newhouse, D. and Evelyn Peters. 2003 "Introduction." In Not Strangers in These Parts: Urban Aboriginal Peoples, ed. David Newhouse and Evelyn Peters. Ottawa: Policy Research Initiative.

Norris, M.J. 1985. "Migration Patterns of Status Indians in Canada, 19761981." Paper prepared for the Demography of Northern and Native Peoples in Canada, Canadian Population Society session, Statistics Canada.

Norris, M.J. and Dan Beavon. 2000. "Aboriginal Mobility and Migration: The Urban Experience, 1991 to 1996." Indian and Northern Affairs Canada (INAC) Presentation to the Urban Aboriginal Strategy National Workshop, Regina, May 11-12, 2000.

Norris, M.J. and S.J. Clatworthy. 2003a. "Aboriginal Mobility and Migration within Urban Canada: Outcomes, Factors and Implications." In Not Strangers in These Parts: Urban Aboriginal Peoples, ed. David Newhouse and Evelyn Peters, 51-78. Ottawa: Policy Research Initiative.

- - - 2003b. "Aboriginal Mobility and Migration within Urban Canada: Outcomes, Factors and Implications: 2001 Census Update." Presentation at the joint PAA/CPS session "Demography of North American Aboriginal Populations," annual meeting of the Population Association of America, Minneapolis, MN.

Norris, M.J., Marty Cooke, and Stewart Clatworthy. 2003. “Aboriginal Mobility and Migration Patterns and the Policy Implications." In Aboriginal Conditions: Research as a Foundation for Public Policy, ed. J. White, P. Maxim and D. Beavon, 108-29. Vancouver: UBC Press. 
Norris, M.J., M. Cooke, E. Guimond, D. Beavon, and S. Clatworthy. 2004. "Registered Indian Mobility and Migration in Canada: Patterns and Implications." In Population Mobility and Indigenous Peoples in Australasia and North America, ed. J. Taylor and M. Bell, 136-60. Routledge: London.

Peters, Evelyn. 2000. "Aboriginal People in Urban Areas.” In Visions of the Heart, Canadian Aboriginal Issues. 2nd ed., ed. David Long and Olive Patricia Dickason, 237-70. Toronto: Harcourt.

Siggner, A. J. 1977. "Preliminary Results from a Study of 1966-1971 Migration Patterns Among Status Indians in Canada.” Department of Indian Affairs and Northern Development (DIAND), Ottawa.

Siggner, A.J. and Rosalinda Costa. 2005 "Aboriginal Conditions in Census Metropolitan Areas, 1981-2001," Statistics Canada. Published by authority of the Minister responsible for Statistics Canada, (C) Minister of Industry, 2005, Catalogue no. 89-613-MIE, No. 008

Sharzer, Stephen. 1985. "Native People: some issues.” In Research Studies of the Commission on Equality in Employment, ed. Judge R.S. Abella, 549-88. Ottawa: Department of Supply and Services, Cat. no. M.P.43-157/2-1985E.

Snipp, C.M. 2009. “The Urbanization of American Indians and Alaska Natives in the United States: An Historic Overview and Recent Demographic Data." Paper prepared for workshop on "Indigenous Urbanization in International Perspective," Departments of Native Studies and Geography, University of Saskatchewan, Saskatoon.

Stanbury, W.T. 1974. "Poverty among British Columbia Indians living offreserves.” Canadian Welfare 50: 20-21, 31-32.

Statistics Canada. 1971. Census of Canada, "Ethnic Groups." Catalogue no. 92-723, vol. 1, part 3. Ottawa: Statistics Canada.

Statistics Canada. 1974. Perspective Canada: A compendium of social statistics / prepared in the Office of the Senior Advisor on Integration, 
Statistics Canada. Published under the authority of the Minister of Industry, Trade and Commerce, Catalogue no. 11-507E.

Statistics Canada. 1981. Census of Canada, "Language, ethnic origin, religion, place of birth, schooling." Catalogue nos. 93-929-93-935, vol. 2 (Provincial series). Ottawa: Statistics Canada.

Statistics Canada. 2008. Aboriginal identity population by age groups, median age and sex, 2006 counts, for Canada and census metropolitan areas and census agglomerations - 20\% sample data (table). Aboriginal Peoples Highlight Tables. 2006 Census. Statistics Canada Catalogue no. 97-558-XWE2006002. Ottawa. http://www12.statcan. ca/english/census06/data/highlights/aboriginal/index.cfm?Lang=E.

Statistics Canada. 2010. “2006 Census Dictionary,” Census Operations Division, Census Year 2006. Published by authority of the Minister responsible for Statistics Canada, (C) Minister of Industry, January 2010, Catalogue no. 92-566-X.

Statistics Canada. 2011 "Incompletely enumerated Indian reserves and Indian settlements." http://www12.statcan.ca/censusrecensement/2006/ref/notes/aboriginal-autochtones-eng.cfm. 